\title{
Flora da Bahia: Leguminosae - Aliança Chloroleucon (Mimosoideae: Ingeae)
}

\author{
Priscilla Gomes Cardoso de Almeida ${ }^{1^{*}}$, Élvia Rodrigues de Souza $^{2, a} \&$ Luciano Paganucci de Queiroz ${ }^{1, b}$ \\ ${ }^{1}$ Departamento de Ciências Biológicas, Universidade Estadual de Feira de Santana, Bahia, Brasil. \\ ${ }^{2}$ Departamento de Educação, Universidade do Estado da Bahia - Campus VIII, Paulo Afonso, Bahia, Brasil.
}

\begin{abstract}
Resumo - É apresentado o levantamento florístico de Blanchetiodendron, Chloroleucon e Leucochloron no estado da Bahia, Brasil. Foram encontradas cinco espécies de Chloroleucon (C. acacioides, C. dumosum, C. extortum, C. foliolosum e C. tortum), duas de Leucochloron (L. limae e L. minarum) e a única espécie de Blanchetiodendron (B. blanchetii). São apresentadas chave de identificação para gêneros e espécies, descrições, comentários para os táxons, além de ilustrações e mapas de distribuição das espécies na Bahia.

Palavras-chave adicionais: Caatinga, florística, taxonomia.
\end{abstract}

\begin{abstract}
Flora of Bahia: Leguminosae - Chloroleucon Alliance (Mimosoideae: Ingeae)) - A floristic survey of the genera Blanchetiodendron, Chloroleucon and Leucochloron is presented for the state of Bahia, Brazil. Five species of Chloroleucon (C. acacioides, C. dumosum, C. extortum, C. foliolosum and C. tortum), two of Leucochloron (L. limae and L. minarum) and the only species of Blanchetiodendron (B. blanchetii) were recognised. Identification keys to genera and species, descriptions and comments for taxa, as well as illustrations and distribution maps of the species in Bahia, are presented.
\end{abstract}

Additional key words: Caatinga, floristics, taxonomy.

\section{Aliança Chloroleucon \\ (sensu Lewis \& Rico Arce 2005)}

Arbustos ou árvores, com espinhos ou inermes. Gemas com escamas peruladas. Estípulas geralmente caducas. Folhas bipinadas; nectários peciolares; nectários adicionais na raque presentes ou não; pinas opostas; parafilídios presentes ou não; folíolos oblongos ou lineares, pinado-palmados ou palmados, glabros ou indumentados. Glomérulos globosos ou obcônicos, pedunculados, solitários, fasciculados ou agrupados em pseudorracemos não folhosos, homomórficos ou heteromórficos com flores centrais diferenciadas das periféricas principalmente pelo comprimento do tubo estaminal; brácteas caducas ou persistentes, triangulares, lineares, oblanceoladas ou largo-oblanceoladas. Flores pentâmeras; cálice cilíndrico a campanulado, lacínias deltoides; corola infudibuliforme a campanulada, lacínias deltoides, agudas ou cuneadas; androceu monadelfo, tubo estaminal incluso ou exserto à corola, filetes 10-51; ovário séssil a subséssil, glabro ou indumentado, nectário floral presente ou ausente. Fruto folículo ou legume, oblongo, linear, falcado, torcido, aleatoriamente torcido ou espiralado, glabro ou indumentado; valvas planocompressas, elevadas na região das sementes, papiráceas a carnosas. Sementes elipsoides ou lenticulares, planocompressas; testa ligeiramente rugosa ou lisa, óssea, pleurograma presente ou ausente.

Barneby \& Grimes (1996) estabeleceram cinco alianças genéricas em Ingeae. Em sua circunscrição original, a aliança Chloroleucon agrupava os gêneros

\footnotetext{
*Autora para correspondência: pgca.bio@gmail.com;

aelviasouza@yahoo.com.br; bluciano.paganucci@gmail.com

Editor responsável: Alessandro Rapini

Submetido: 15 nov. 2013; aceito: 29 mar. 2014

Publicação eletrônica: 26 jan. 2015; versão final: 2 fev. 2015
}

Blanchetiodendron, Chloroleucon e Leucochloron e tinha distribuição restrita à região neotropical, principalmente em formações tropicais sazonalmente secas, apresentando como principais sinapomorfias morfológicas a presença de gemas com escamas peruladas e a supressão das folhas nos nós proximais. Lewis \& Rico Arce (2005) acrescentaram a esta aliança os gêneros Cathormion Hassk., do sudeste da Ásia e norte da Austrália, e Thailentadopsis Kosterm., do sudeste asiático, embora eles não compartilhem as principais características da aliança.

$\mathrm{Na}$ Bahia, ocorrem os três gêneros neotropicais da Aliança Chloroleucon (Lima et al. 2013). A maioria das espécies de Chloroleucon e Leucochloron que ocorrem no estado apresentam folhas que se expandem durante a floração, de modo que os espécimes com flores, em geral, apresentam folhas ainda jovens. As medidas aqui apresentadas referemse apenas às folhas totalmente desenvolvidas e o número de folíolos é apresentado para as maiores pinas de cada folha.

\section{Chave para os gêneros}

1. Folhas com parafilídios lineares ou filiformes; glomérulos globosos; frutos indumentados

3. Leucochloron

1'. Folhas sem parafilídios; glomérulos obcônicos; frutos glabros.

2. Plantas com pelo menos alguns ramos com espinhos axilares, pareados ou solitários; glomérulos axilares, solitários ou fasciculados; flores sésseis ou subsésseis (pedicelo das flores periféricas $\leq 1 \mathrm{~mm}$ compr.); ovário glabro; nectário floral ausente; frutos lineares, falcados, torcidos ou espiralados; sementes elipsoides, biconvexas, com pleurograma completo ou em forma de "U" .

2. Chloroleucon 
2'. Plantas inermes; glomérulos agrupados em pseudorracemos não folhosos; flores pediceladas (pedicelo das flores periféricas $\geq 1,5 \mathrm{~mm}$ compr.); ovário indumentado; nectário floral presente, circundando o ovário das flores centrais; frutos oblongos, plano-compressos; sementes orbiculares, plano-compressas, sem pleurograma 1. Blanchetiodendron

\section{Blanchetiodendron Barneby \& J.W.Grimes}

Árvore inerme. Estípulas caducas. Folhas totalmente desenvolvidas na floração; nectários peciolares sésseis; nectários adicionais na raque presentes ou não; parafilídios ausentes; folíolos oblongos, venação pinado-palmada, glabros ou indumentados. Glomérulos obcônicos, agrupados em pseudorracemos não folhosos, heteromórficos, flor central diferenciada das periféricas pelo tamanho do perianto e comprimento do tubo estaminal; brácteas caducas. Flores pediceladas; cálice campanulado, lacínias deltoides; corola campanulada, lacínias agudas; tubo estaminal incluso ou exserto à corola, filetes 26-46; ovário séssil a subséssil, indumentado; nectário floral presente nas flores centrais. Fruto legume, oblongo, glabro; valvas plano-compressas, elevadas na região da semente. Sementes orbiculares, plano-compressas, margem hialina; testa ligeiramente rugosa, óssea, sem pleurograma.

1.1. Blanchetiodendron blanchetii (Benth.) Barneby \& J.W.Grimes, Mem. New York Bot. Gard. 74(1): 129. 1996. Enterolobium blanchetii Benth., London J. Bot. 3: 224. 1844.

Figuras 1-3.

Nomes populares: canela-de-burro, canzil, angico (Barneby \& Grimes 1996).

Árvore 3-10 $\mathrm{m}$ alt. Estípulas $3-5 \times 1-1,5 \mathrm{~mm}$, lineares, membranáceas. Folhas com pecíolo 1,7-5,2 cm compr.; raque 1,9-5,5 cm compr.; nectários peciolares a 9-32 $\mathrm{mm}$ da base do pecíolo, nectários adicionais, quando presentes, entre o último par de pinas; pinas 2 ou 3(4) pares, 5,3-11,6 cm compr.; folíolos 10-13 pares, 10-20,2 × 4,3-8 mm, oblongos, ápice cuspidado, base obliquamente obtusa, papiráceos ou cartáceos. Glomérulos heteromórficos, pedúnculo $0,5-1,5 \mathrm{~cm}$ compr. Flores periféricas com pedicelo 1,5-6 mm compr.; cálice 1,1-2,3 mm compr.; corola 2,5-4,2 mm compr.; filetes 26-38, 10,5-17,6 mm compr., livres por 9-14 mm compr.; nectário ausente; ovário 1-1,7 mm compr., cilíndrico, estilete 9-20 mm compr. Flores centrais com pedicelo $0,1-0,5 \mathrm{~mm}$; cálice 1,6-4,7 mm compr.; corola 3,7-5,4 mm compr.; filetes 30-46, 13,5-19 mm compr., livres por 7,5-10 mm compr.; nectário carnoso circundando o ovário, 0,7-1 mm compr.; ovário 1,1-2,1 mm compr., cilíndrico, estilete 11,5-18 mm compr. Frutos 13,2$20,5 \times 2-4,3 \mathrm{~cm}$, ápice cuspidado a caudado, base aguda, margem levemente ondulada, mas não constrita entre as sementes; valvas papiráceas. Sementes 7-10,5 $\times 7-11 \times 0,2-1,5 \mathrm{~mm}$; testa marrom.

Endêmica do Brasil, ocorrendo na Bahia e em Minas Gerais, em florestas semidecíduas (Barneby \& Grimes 1996). Na Bahia, é encontrada principalmente na região da Chapada Diamantina. C7, D5, D6, D7, E6, E7, E8, F5, F6, F7: Caatinga (florestas estacionais deciduais e semideciduais). Floração: outubro a dezembro; frutificação: novembro a agosto.

Material selecionado - Abaíra, Catolés, $13^{\circ} 17^{\prime} \mathrm{S}, 4^{\circ} 52^{\prime} \mathrm{W}, 28$ dez. 1988 (fl.), R.M. Harley 27855 (SPF); Barra do Mendes, a 35km de Barra do Mendes, $11^{\circ} 48^{\prime} \mathrm{S}, 42^{\circ} 03^{\prime} \mathrm{W}, 27$ jan. 2001 (fr.), M.L. Guedes 8167 (HUEFS); Caen, ca. 1 km da BR-324 na estrada para Caen, $11^{\circ} 11^{\prime} \mathrm{S}, 40^{\circ} 25^{\prime} \mathrm{W}, 22$ ago. 1993 (fr.), L.P. Queiroz 3550 (CEPEC, HUEFS, MBM); Campo Formoso, Povoado de Delfino, fazenda Retiro, 22 out. 1971 (fl.), F.B. Ramalho 30 (RB); Caturama, Morro Branco, 13¹7'45"S, 42¹2'01"W, 6 jul. 2007 (fr.), A.A. Conceição 2428 (HUEFS); Cruz das Almas, nov. 1981 (fr.), G.C.P. Pinto 242 (CEPEC); Gentio do Ouro, $11^{\circ} 27^{\prime} \mathrm{S}, 42^{\circ} 25^{\prime} \mathrm{W}, 30$ nov. 1971 (fl.), C.A. Miranda 42 (HRB, RB); Iraquara, ca. 3 km norte de Água de Rega, na estrada para Souto Soares, local conhecido como ladeira do Véio Dedé, 1208'58"S, 4146'17"W, 23 jul. 1993 (fr.), L.P. Queiroz 3406 (CEPEC, HUEFS, MBM); Irecê, Barra do Mendes, divisa com Ipupiara, Morrão, $11^{\circ} 48^{\prime} 27^{\prime \prime} \mathrm{S}, 42^{\circ} 14^{\prime} 05^{\prime \prime} \mathrm{W}, 25$ out. 2009 (fl.), M.L. Guedes 16128 (ALCB, HUEFS, MBM); Itaberaba, parte da ARIE pertencente a Itaberaba, fazenda Bom Jardim, estância Baleeiro, 12²0'06"S, 40²8'33"W, 14 nov. 2004 (fl., fr.), L.P. Queiroz 9813 (HUEFS); Livramento do Brumado, ca. $4 \mathrm{~km}$ norte de Livramento do Brumado, na estrada para Rio de Contas, 133' $28^{\prime \prime S}$,

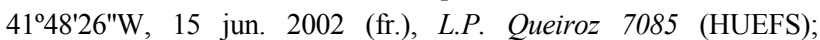
Macaúbas, 26 nov. 2004 (fl.), G. Hatschbach 78553 (MBM); Maracás, Rodovia BA-026, 17 nov. 1978 (fl.), S.A. Mori, T.S. Santos \& C.B. Thompson 11086 (CEPEC, RB); Mirangaba, $8 \mathrm{~km}$ de Mirangaba, 1 set. 1981 (fr.), J.D.C.A. Ferreira 64 (HRB); Morro do Chapéu, estrada Duas Barras do Morro-Utinga, 1 abr. 1986 (fr.), H.P. Bautista 1078 (RB); Paraguaçu, 12²4'55"S, 4049'22"W, 28 abr. 2001 (fr.), D.M. Loureiro 200 (ALCB); Paramirim, 13¹7'47"S, 42 ${ }^{\circ} 14^{\prime} 50 " \mathrm{~W}, 29$ abr. 2007 (fr.), A.A. Conceição 1981 (ALCB, HUEFS); Piemonte da Diamantina, 23 abr. 2010 (fr.), M.L. Guedes 16970 (ALCB, MBM); Piritiba, ca. 25 km norte da BA-052 (Estrada

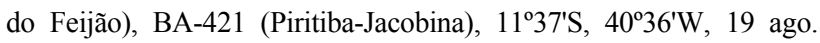
1993 (fr.), L.P. Queiroz \& N.S. Nascimento 3467 (CEPEC, HUEFS); Rio de Contas, Povoado de Baixa Funda, próximo de Arapiranga, 6,4 km NE de Rio de Contas, 1331'40"S, 41 466'59"W, 14 fev. 2007 (fr.), R.M. Harley 55564 (HUEFS); Ruy Barbosa, 14 out. 1978 (fl.), A.P. Araújo 75 (CEPEC); Seabra, estrada Piatã-Seabra, Alagadiço, nov. 1992 (fl.), W. Ganev. s.n. (HUEFS 13718); Senhor do Bonfim, Serra de Santana, 26 dez. 1984 (fl., fr.), R.M. Silva (CEPEC 40597); Wagner, entre as fazendas Bonito e Bonito do Meio, às margens do rio Bonito, $12^{\circ} 15^{\prime} 0^{\prime \prime} \mathrm{S}, 41^{\circ} 13^{\prime} 59^{\prime \prime} \mathrm{W}, 9$ abr. 1986 (fr.), A.C. Sarmento 872 (ALCB, HRB, HUEFS, RB).

A espécie pode ser reconhecida pelos glomérulos obcônicos agrupados em pseudorracemos não folhosos, acima ou na axila das folhas, presença de gemas peruladas e frutos com valvas membranáceas, planocompressas, mas elevadas na região da semente, principalmente quando maduros. A presença de um nectário floral em volta da base do ovário das flores centrais está sendo relatada aqui pela primeira vez para a espécie. 


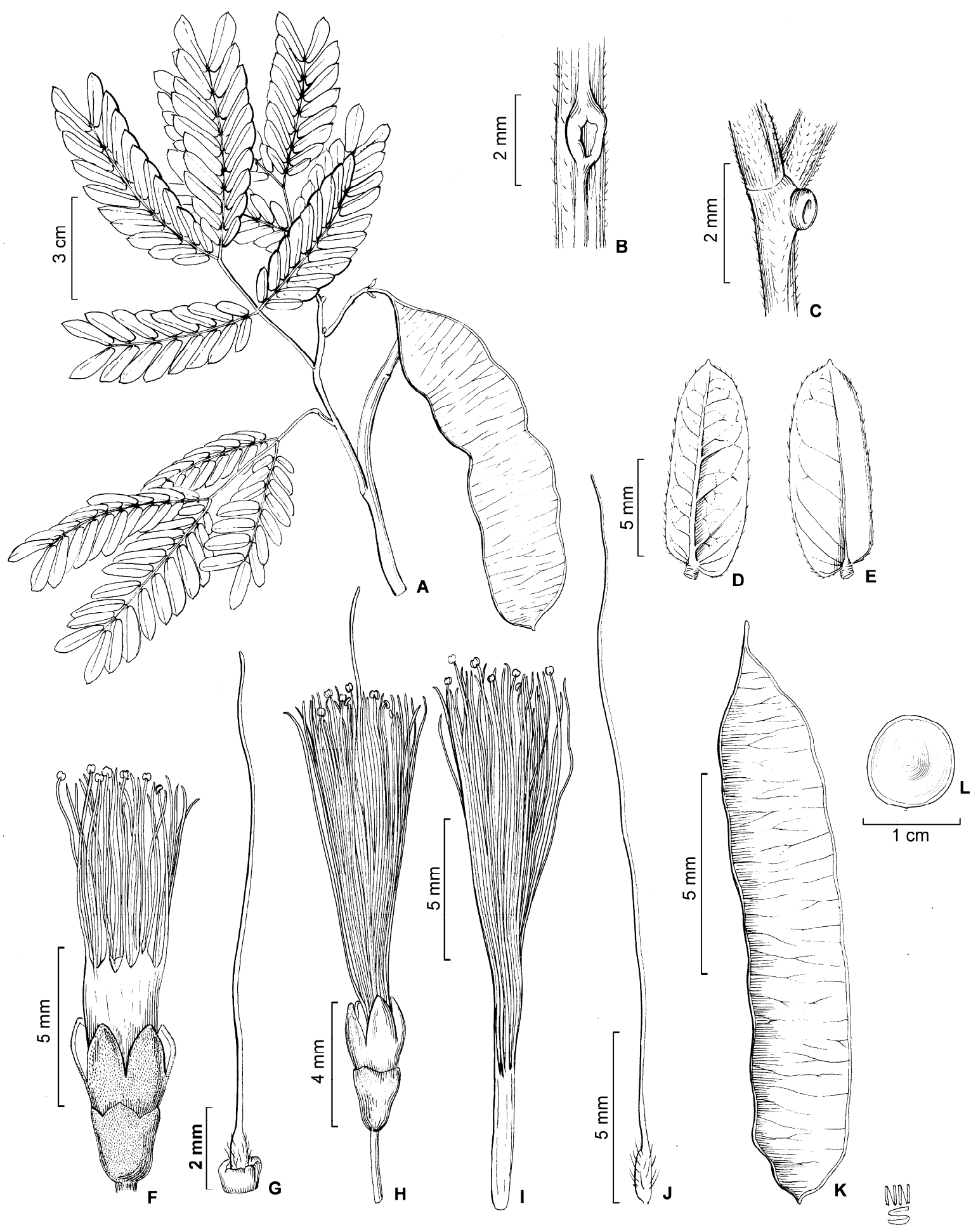

Figura 1. Blanchetiodendron blanchetii: A- ramo com fruto; B- nectário peciolar (vista frontal); C- nectário na raque entre o último par de pinas; D- face abaxial do folíolo; E- face adaxial do folíolo; F- flor central; G- Gineceu e nectário floral (flor central); H- flor periférica; I- androceu (flor periférica); J- gineceu (flor periférica); K- fruto (imaturo); L- semente. (A- Queiroz 7670; B-E, L- Queiroz 3550, F-J- Harley 55563; K- Sarmento 872)

2. Chloroleucon (Benth.) Britton \& Rose

Arbusto ou árvore; ramos com espinhos axilares, retos, frequentemente pareados, às vezes com ramos inermes na mesma planta. Estípulas geralmente caducas. Folhas geralmente se expandindo após a floração, raramente com folhas desenvolvidas junto às flores; nectários peciolares sésseis ou estipitados; nectários adicionais na raque, entre o penúltimo e o último ou apenas no último par de pinas; parafilídios ausentes; folíolos lineares ou oblongos, glabros ou indumentados, venação palmada. Glomérulos obcônicos, pedunculados, solitários ou fasciculados, 


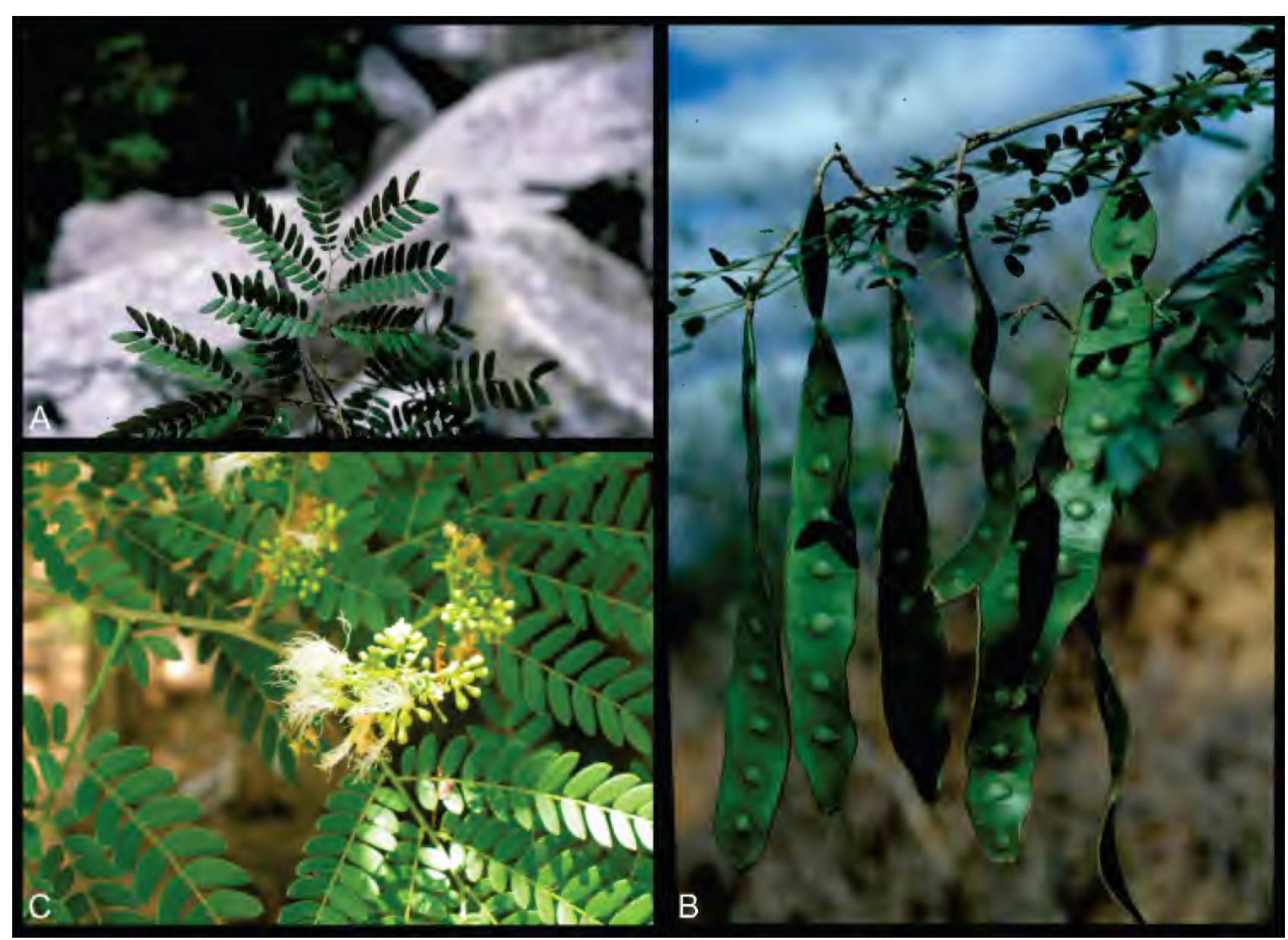

Figura 2. Blanchetiodendron blanchetii: A- folhas; B- fruto; C- inflorescência. (Fotos: L.P. Queiroz)

axilares, homomórficos ou heteromórficos, nesse caso com uma ou duas flores centrais diferenciadas das

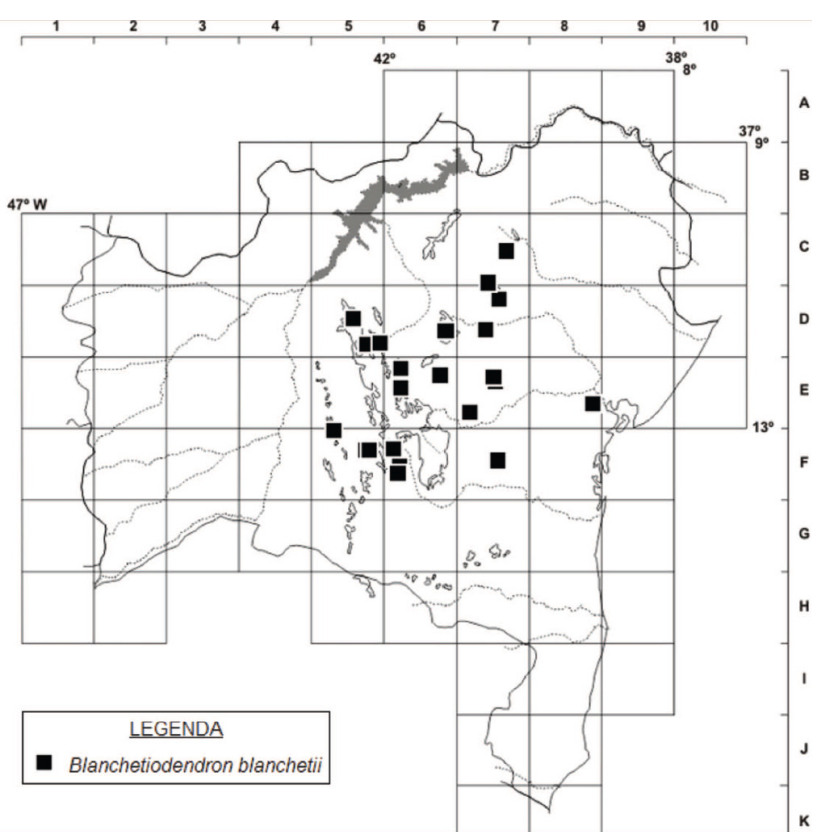

Figura 3. Distribuição geográfica de Blanchetiodendron blanchetii no estado da Bahia. periféricas pelo tamanho do perianto e comprimento do tubo estaminal; brácteas caducas. Flores sésseis ou subsésseis; cálice campanulado, lacínias deltoides, agudas; corola infudibuliforme, lacínias deltoides, agudas; tubo estaminal incluso ou exserto à corola, filetes 10-30; nectário floral ausente; ovário séssil a subséssil, glabro. Fruto legume, linear, falcado, torcido ou espiralado, semimoniliforme (margem superior reta e inferior sinuosa), moniliforme ou não; valvas glabras, cartáceas a carnosas, elevadas na região das sementes. Sementes elipsoides, biconvexas; testa lisa, óssea, pleurograma completo ou em forma de "U".

Chloroleucon distribui-se predominantemente em áreas de Caatinga, confirmando Barneby \& Grimes (1996) e Queiroz (2009). As espécies da Bahia podem ser agrupadas em um grupo com glomérulos heteromórficos (C. acacioides, $C$. extortum, $C$. foliolosum e $C$. tortum) e outro com glomérulos homomórficos $(C$. dumosum $)$. As espécies são diferenciadas principalmente por caracteres dos frutos, tornando a taxonomia do gênero complexa na ausência destes. As plantas geralmente florescem sem folhas e há sobreposição nos caracteres foliares. $\mathrm{O}$ indumento das folhas também não é um bom caráter para separar as espécies, pois varia na mesma espécie. 


\section{Chave para as espécies}

1. Folíolos lineares (relação compr. : larg. $\geq 5: 1$ ); brácteas oblanceoladas; frutos maduros com valvas cartáceas.

2. Folhas com até 5 pares de pinas e 18-28 pares de folíolos por pina; frutos moniliformes, torcidos ao longo do comprimento

2.3. C. extortum

2'. Folhas com 6-10 pares de pinas e 30-43 pares de folíolos por pina; frutos não moniliformes, espiralados

2.1. C. acacioides

1'. Folíolos oblongos a obovais (relação compr. : larg. $<5: 1$ ); brácteas lineares; frutos maduros com valvas carnosas.

3. Glomérulos homomórficos; frutos semimoniliformes 2.2. C. dumosum

3'. Glomérulos heteromórficos; frutos não moniliformes.

4. Pinas com 6-8 pares de folíolos; frutos espiralados ....................... 2.5. C. tortum

4'. Pinas com mais de 8 pares de folíolos; frutos falcados 2.4. C. foliolosum

2.1. Chloroleucon acacioides (Ducke) Barneby \& J.W.Grimes, Mem. New York Bot. Gard. 74(1): 141. 1996. Pithecolobium acacioides Ducke, Arch. Jard. Bot. Rio de Janeiro 3: 69. 1922.

Figuras 4, 5A-D e 9.

Nomes populares: arapiraca, esponjeira, jurema, jurema-branca, pereira (Barneby \& Grimes 1996).

Arbustos ou árvores 1-10 $\mathrm{m}$ alt., ramos armados ou não. Estípulas 7-9 × 1,5-3 $\mathrm{mm}$, membranáceas, oblanceoladas. Folhas jovens durante a floração; pecíolo 0,7-2,4 cm compr.; raque 2-7,7 cm compr.; nectários peciolares a 4-12 $\mathrm{mm}$ da base do pecíolo, sésseis, nectários adicionais entre o penúltimo e o último par de pinas; pinas 6-10 pares, 2-4,9 cm compr.; folíolos 30 43 pares, 3,2-6,5 × 0,3-1 mm, lineares, ápice agudo, base obliquamente truncada, membranáceos, discolores na face abaxial, pilosos apenas na margem. Glomérulos heteromórficos, pedúnculo $0,5-1,5 \mathrm{~cm}$ compr., brácteas 0,5-0,6 compr., oblanceoladas. Flores periféricas subsésseis; cálice 1,1-2,2 mm compr.; corola 3,9-6,5 mm compr.; filetes 10-12, 11,2-16,5 mm compr., livres por 9-12 mm compr.; ovário 1-1,5 mm compr., cilíndrico, glabro, estilete $7-15 \mathrm{~mm}$ compr. Flores centrais sésseis; cálice $0,8-1,5 \mathrm{~mm}$ compr.; corola 4 6,5 mm compr.; filetes 10-20,9-14,7 mm compr., livres por 2,5-5,5 mm compr.; ovário ca. $1 \mathrm{~mm}$ compr., cilíndrico, glabro, estilete 7,6-14,4 mm compr. Frutos 15-19 × 0,6-1,1 cm, estipitado, espiralado, ápice acuminados a obtusos ou arredondados, base atenuada, não moniliforme; valvas plano-compressas, elevadas na região das sementes, papiráceas. Sementes ca. $5 \times 3 \times 2$ $\mathrm{mm}$; testa creme, marrom dentro do pleurograma, pleurograma quase completo.

Guiana Francesa e Brasil (estados do Amapá, Pará, Tocantins, Mato Grosso, Goiás, Maranhão, Ceará,
Pernambuco, Piauí e Bahia; Barneby \& Grimes 1996; Iganci 2013). Na Bahia, é encontrada apenas no noroeste do estado. D2: Caatinga. Floração: abril a agosto; frutificação: junho a janeiro.

Material selecionado - Formosa do Rio Preto, estrada para fazenda Estrondo, pelo Riachão, 15 ago. 2009 (fr.), J.E. Meireles 732 (HUEFS, HRB, MBM).

Material adicional - BRASIL. CEARÁ: Serra de Baturité, sítio Caridade, 15 nov. 1939 (fr.), J.E. Leite 588 (RB); Dunas do Pecém, 5 nov. 2003 (fr.), M.F. Lima s.n. (EAC 33072). PIAUÍ: Guadalupe, estrada de barro para barragem de Boa Esperança, 22 nov. 2005 (fl.), A.M. Miranda 5307 (HUEFS).

Chloroleucon acacioides é comumente confundida com $C$. foliolosum pela semelhança no número de pinas e por terem inflorescências heteromórficas semelhantes. No entanto, C. foliolosum possui menos folíolos nas pinas (10-27 pares) e apresenta frutos falcados.

2.2. Chloroleucon dumosum (Benth.) G.P.Lewis, Legumes Bahia: 165. 1987. Pithecolobium dumosum Benth., London J. Bot. 2: 223. 1844.

Figuras 6, 7 e 14.

Nomes populares: arapiraca, jurema-branca, paurósea, vinhático-de-espinho (Barneby \& Grimes 1996).

Arbustos ou árvores 2,5-9 $\mathrm{m}$ alt., ramos com espinhos ou inermes. Estípulas ca. $5 \times 1,5 \mathrm{~mm}$, membranáceas, oblanceoladas. Folhas completamente desenvolvidas ou se expandindo durante a floração; pecíolo 0,6-3 cm compr.; raque 2-6 cm compr.; nectários peciolares a 4-12 $\mathrm{mm}$ da base do pecíolo, sésseis, nectários adicionais entre o último par de pinas e raramente entre o penúltimo par de pinas; pinas 35(-7) pares, 2,5-9,2 cm compr.; folíolos 11-22 pares, 4,5-19 × 0,9-4,5 mm, oblongos, ápice cuneado a obtuso, base obliquamente obtusa, papiráceos, pubescente a velutino. Glomérulos homomórficos, pedúnculo $0,6-2,5 \mathrm{~cm}$ compr., brácteas $1-2,5 \mathrm{~mm}$ compr., lineares. Flores sésseis a subsésseis; cálice 1,1-2,4 mm compr.; corola 3,8-9,8 mm compr.; filetes 16-21, 11,5-29,5 mm compr., livres por 5-10 $\mathrm{mm}$ compr.; ovário 1-1,9 mm compr., cilíndrico, glabro, estilete 10-22 mm compr. Frutos $8-21,5 \times 0,8-1,2$ $\mathrm{cm}$, sésseis, glabros, irregularmente torcidos ao longo do comprimento, semimoniliformes, ápice arredondado a cuspidato, base atenuada; valvas constritas entre as sementes, cartáceas (frutos imaturos) a carnosas (maduros). Sementes 6,5-7 × ca. 5 × 3-3,5 mm; testa marrom-clara, pleurograma completo.

Brasil (Ceará, Paraíba, Pernambuco, Rio Grande do Norte, Bahia e Minas Gerais), nos domínios da Caatinga e da Mata Atlântica (florestas costeiras perturbadas; Barneby \& Grimes 1996). Na Bahia, ocorre principalmente na região da Chapada Diamantina. D4, D5, E2, E6, E7, E8, E9, F3, F6, G5, G8, H8: Caatinga. Floração: julho a fevereiro; frutificação: agosto a abril. 


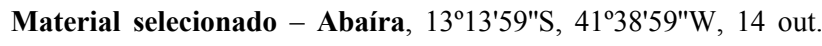
2006 (fl.), M.L. Guedes 12537 (ALCB); Anguera, fazenda Retiro, ca. $18 \mathrm{~km}$ de Feira de Santana, na Estrada do Feijão, sentido Ipirá, $12^{\circ} 9^{\prime} 42^{\prime \prime S}, 39^{\circ} 11^{\prime 2}$ "W, 22 maio 2007 (est.), D. Cardoso 1921 (HUEFS); Aramari, 15 jul. 1981 (fl.), B.C. Bastos 156 (CEPEC); Cachoeira, Ipuaçu, set. 1980 (fl.), Grupo Pedra do Cavalo 763
(CEPEC, HUEFS, IPA); Contendas do Sincorá, 13\%48'04"S, 41 02'36"W, 31 out. 1979 (fl.), A. Araújo 106 (RB); Coribe, 24,4 km sul de São Felix do Coribe, na estrada para Coribe, $13^{\circ} 35^{\prime} 10^{\prime \prime S}$, 44 10'12"W, 10 abr. 2007 (est.), L.P. Queiroz 12720 (HUEFS); Gentio do Ouro, Serra do Açuruá, estrada pra Xique-Xique, 10 out. 1990 (fr.), H.C. Lima 3933 (CEPEC, RB); Irecê, Barra do Mendes,

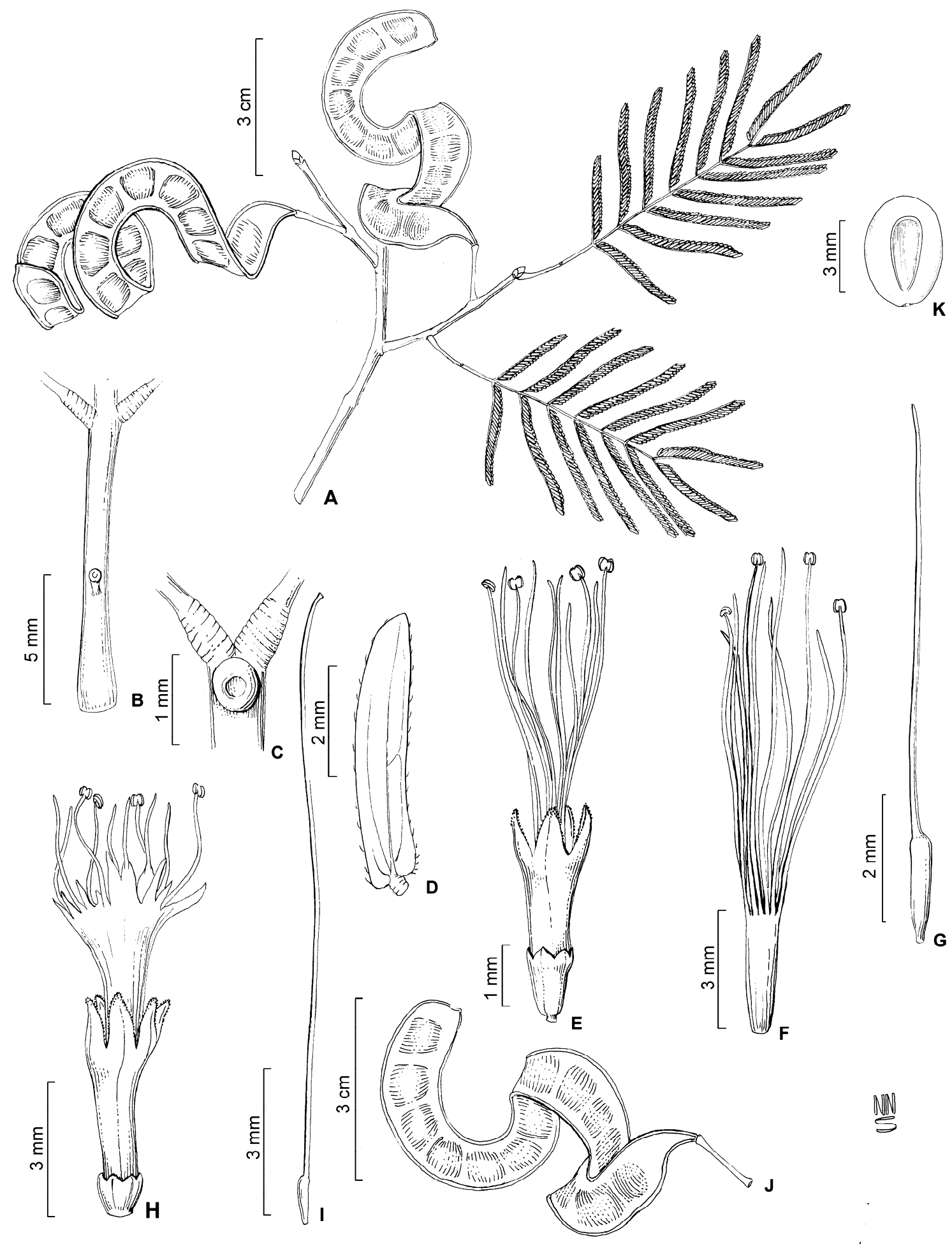

Figura 4. Chloroleucon acacioides: A- ramo com frutos; B- pecíolo (vista frontal) com nectário peciolar; C- nectário na raque, entre o último par de pinas; D- folíolo (face adaxial); E- flor periférica; F- androceu (flor periférica); G- Gineceu (flor periférica); H- flor central; I- gineceu (flor central); J- fruto; K- semente. (A-D, J- Meireles 732; E-I- Miranda 5307; K- Lima s.n. EAC 33072) 


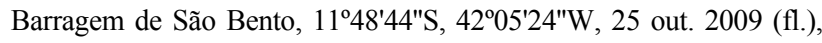
M.L. Guedes 16101 (ALCB, HUEFS, MBM); Ibipeba, Lapão, Morro

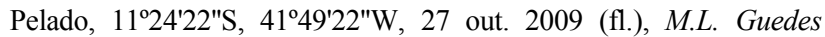
16180 (ALCB, HUEFS, MBM); Iraquara, em frente a posto de gasolina Nova Iraquara, 20 fev. 2013 (fl.), P.G.C. Almeida 8 (HUEFS); Itapitanga, 2 ago. 1971 (fr.), R.S. Pinheiro 1330 (CEPEC); Jacobina, estrada Jacobina-Feira de Santana, Km 1, periferia de Jacobina, 21 set. 1996 (fl., fr.), G.P. Silva 3631 (HUEFS); Malhada, 23 abr. 1932 (fr.), P.C. Porto 2504 (RB); Morpará, beira do Rio Paramirim, 11 ${ }^{\circ} 33^{\prime} \mathrm{S}, 43^{\circ} 16^{\prime} \mathrm{W}, 17$ dez. 2007 (fl.), A.A. Conceição 2733 (HUEFS); Mundo Novo, fazenda Jequitibá, 12²'00"S, 40²9'00"W,
28 fev. 2007 (fl.), P.A. Mello 181 (HUEFS); Palmeiras, BR-242, entroncamento para Irecê, $12^{\circ} 27^{\prime} \mathrm{S}, 41^{\circ} 38^{\prime} \mathrm{W}, 7$ out. 1995 (fr.), G.P. Silva 3087 (HUEFS); Potiraguá, Km 22 da antiga rodovia CamacãItambé, 1532'S, 39³0'W, 26 set. 1979 (fl.), J.L. Hage \& L.A. Mattos Silva 305 (CEPEC, RB); Riachão das Neves, 26 out. 1912 (fl.), $F$. Lehutne 475 (RB); Ruy Barbosa, estrada entre Ruy Barbosa e Barro Duro, 12²17'48"S, 40'27'39"W, 14 nov. 2004 (fl.), L.P. Queiroz 9803

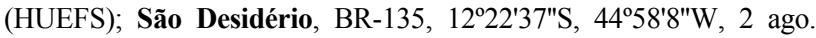
2007 (fr.), R.M. Santos 1713 (HUEFS); Urandi, Serra Geral, caminho

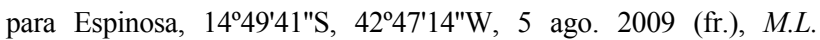
Guedes 15855 (ALCB, HUEFS).

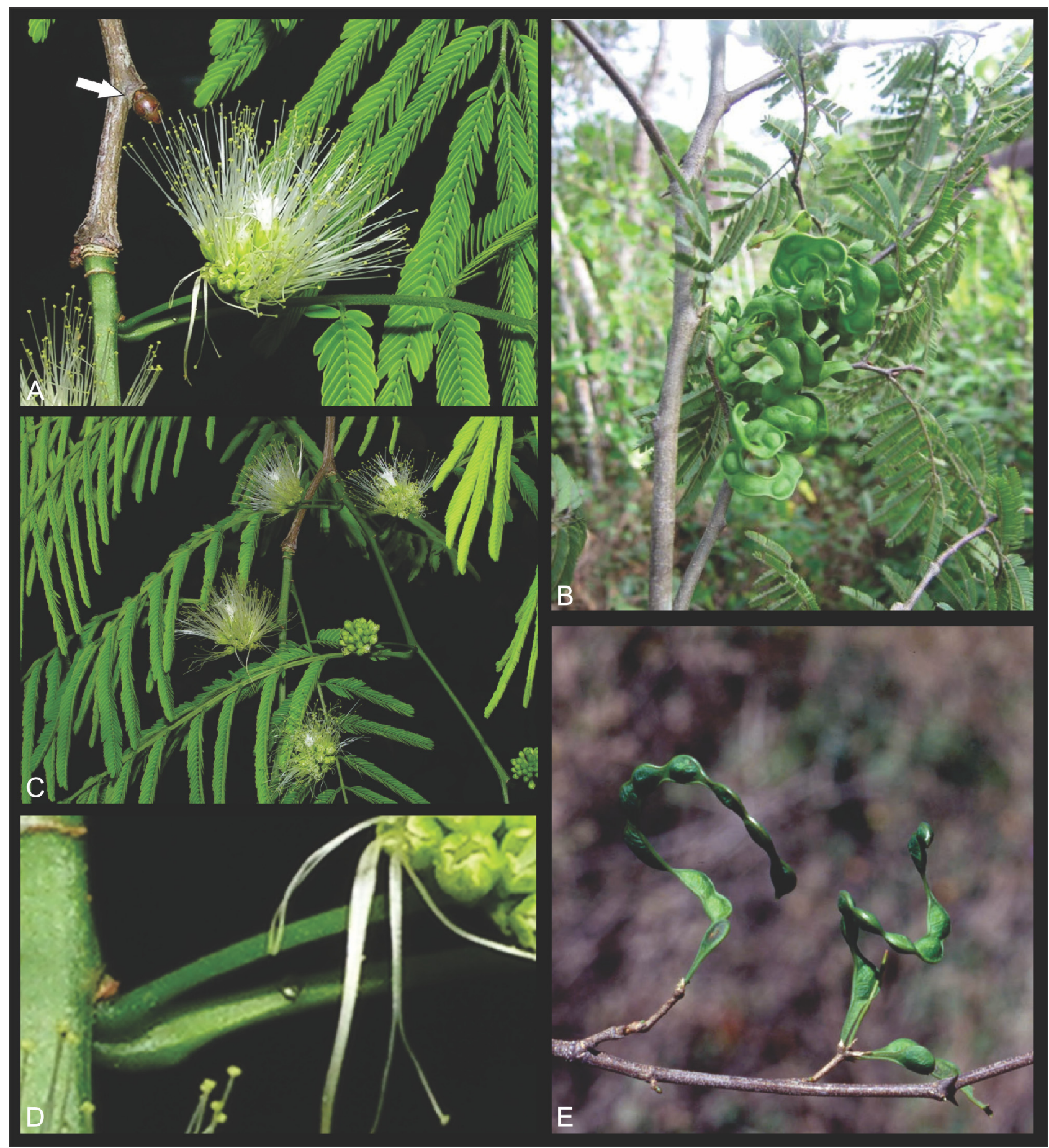

Figura 5. A-D. Chloroleucon acacioides: A- ramo evidenciando a gema perulada (seta) e a inflorescência heteromórfica; B- fruto; C- ramos com inflorescências; D- nectário peciolar. E. Chloroleucon extortum: frutos. (Fotos: A, C, D- D. Cardoso; B- D. Sasaki; E- L.P. Queiroz) 
Chloroleucon dumosum diferencia-se das demais espécies principalmente pelas inflorescências homomórficas. A forma dos frutos varia, a maioria das vezes é aleatoriamente torcido, mas pode ser espiralada em alguns casos. Quando imaturos, seus frutos podem ser confundidos com os de C. acacioides, mas pode ser diferenciada daquela espécie pelo menor número de pinas e de folíolos (6-10 pares de pinas e 30-42 pares de folíolos em $C$. acacioides). $\mathrm{O}$ indumento dos folíolos de C. dumosum apresenta grande variação, não sendo um bom caráter para a identificação da espécie.

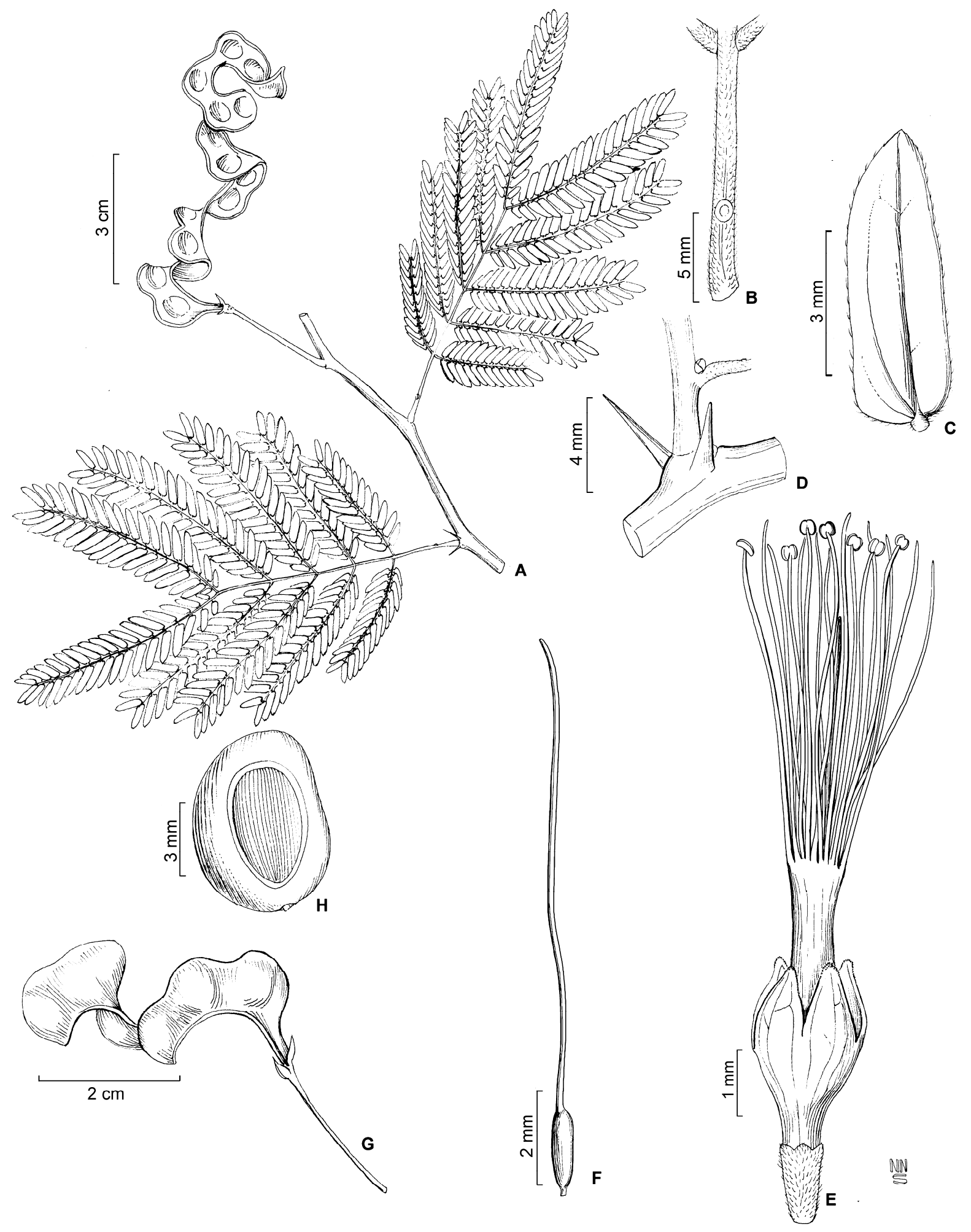

Figura 6. Chloroleucon dumosum: A- ramos com fruto; B- nectário peciolar; C- folíolo (face adaxial); D- espinhos; E- flor; F- gineceu; G- fruto; H- semente. (A, D, G- Queiroz 12772; B, C, E, F, H- Queiroz 9803) 


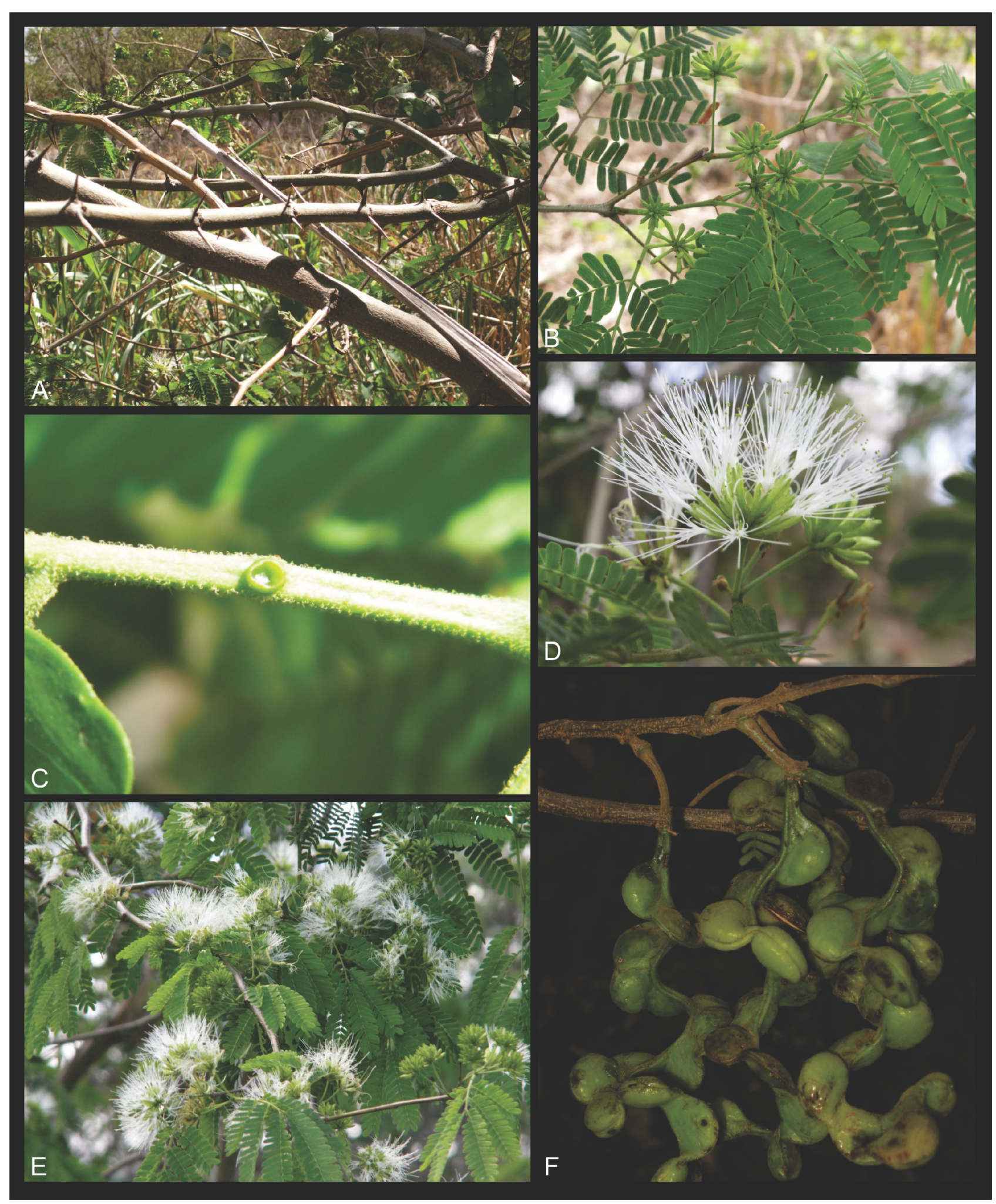

Figura 7. Chloroleucon. dumosum: A- ramos com espinhos; B- inflorescências com flores em botões; C- nectário peciolar; D- inflorescência homomórfica; E- ramos com inflorescências; F- frutos. (Fotos: A-E- E.R. Souza; F- D. Cardoso)

\subsection{Chloroleucon extortum Barneby \& J.W.Grimes,}

Mem. New York Bot. Gard. 74(1): 142. 1996.

Figuras 5E e 8-10.

Arbustos ou árvores 3-4 m alt., ramos armados ou inermes. Estípulas 3,5-5 $\times \quad 1,2-2,1 \quad \mathrm{~mm}$, oblanceoladas, membranáceas. Folhas se expandindo durante a floração; pecíolo $0,5-1,3 \mathrm{~cm}$ compr.; raque 0,9-2,5 cm; nectários peciolares a 3-4 $\mathrm{mm}$ da base do pecíolo, sésseis, nectários adicionais na raque, entre o último par de pinas; pinas 3-5 pares, $1,8-2,5 \mathrm{~cm}$ compr.; folíolos $18-28$ pares, $3,1-5 \times 0,5-1 \mathrm{~mm}$, lineares, ápice cuneado, base obliquamente obtusa, 

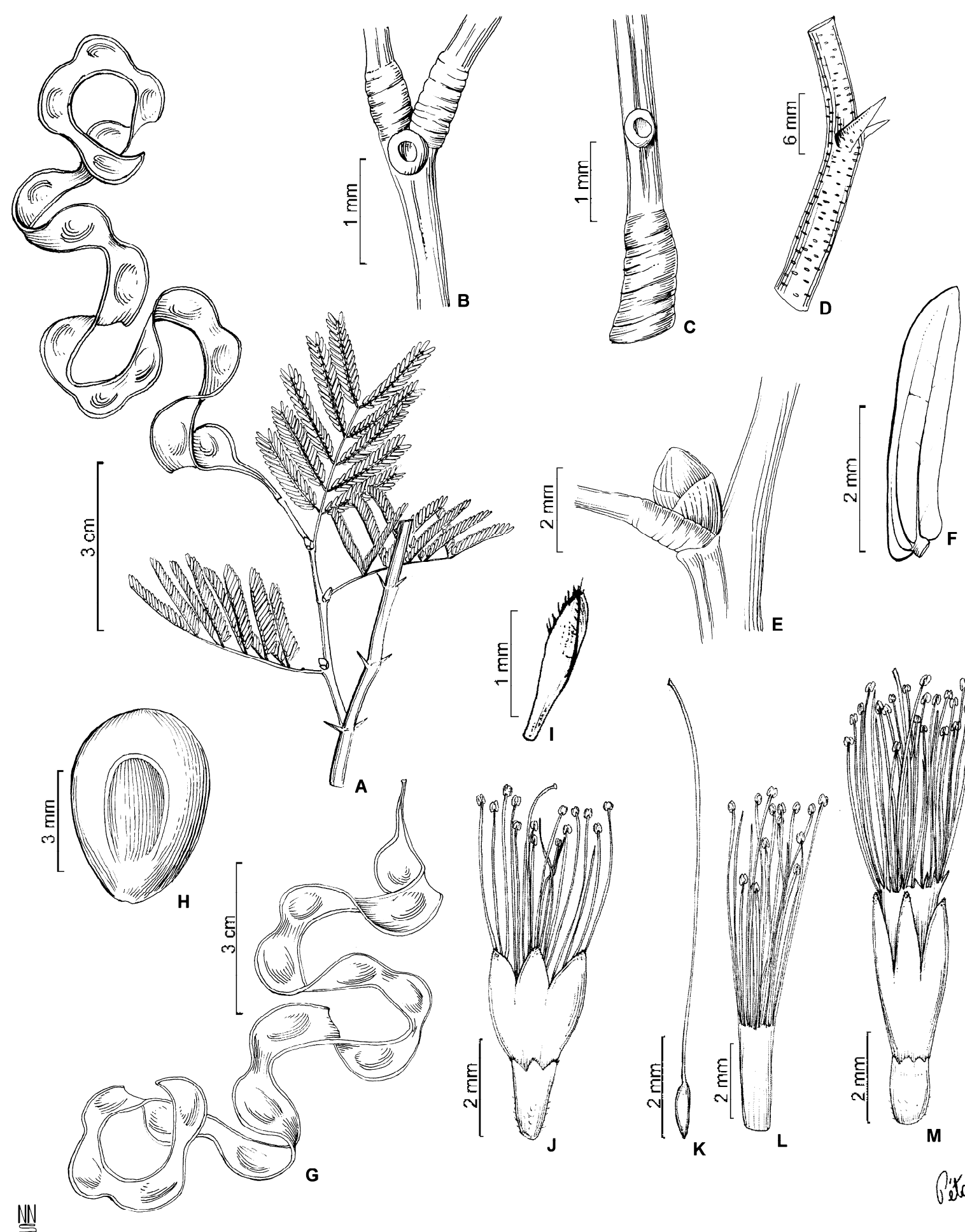

Figura 8. Chloroleucon. extortum: A- ramo com frutos; B- nectário adicional (base do último par de pinas); C- nectário peciolar; D- espinhos; E- gema; F- folíolo; G- fruto; H- semente; I- bráctea; J- flor periférica; K- gineceu (flor periférica); L- androceu (flor periférica); M- flor central; N- gineceu (flor central) (A-H- Queiroz 3973 por Natanael N. Santos; I-N- Neves 278 por Pétala G. Ribeiro).

papiráceos, glabros ou pilosos nas margens. Glomérulos heteromórficos, pedúnculo $8-9 \mathrm{~mm}$ compr., brácteas ca. $1,5 \times 0,3 \mathrm{~mm}$, oblanceoladas. Flores periféricas subsésseis; cálice 1-2 $\mathrm{mm}$ compr.; corola 2,9-4 mm compr.; filetes 17-20, 8,6-12,3 mm compr., livres por $6,2-8,5 \mathrm{~mm}$ compr.; ovário $1,1-1,2$ $\mathrm{mm}$ compr., cilíndrico, glabro, estilete $8,9-13,5 \mathrm{~mm}$ compr. Flores centrais sésseis; cálice 1,3-1,9 mm compr.; corola 3,8-5,1 mm compr.; filetes $20-35,9,5-$ $12,7 \mathrm{~mm}$ compr., livres por $4-6,2 \mathrm{~mm}$ compr.; ovário $1-$ $1,2 \mathrm{~mm}$ compr., séssil, cilíndrico, glabro, estilete 9,210,1 mm compr. Frutos 9-22 × 0,4-0,9 cm, sésseis, 
torcidos ao longo do comprimento, ápice agudo, base atenuada, margens moniliformes; valvas constritas entre as sementes, papiráceas. Sementes 5,5-6 × 3,5-4 × 0,5$1,1 \mathrm{~mm}$; testa marrom-clara, pleurograma em forma de $\mathrm{U}$.

Endêmica da Bahia, é pouco coletada, sendo considerada rara (Queiroz et al. 2009). B9, C7, D5, E6, E7: Caatinga (florestas estacionais semideciduais). Floração: outubro (único registro); frutificação: janeiro a outubro.

Material selecionado -Gentio do Ouro, $3 \mathrm{~km}$ de Gentio do Ouro, na estrada para Mirorós, 17 jun. 1994 (fr.), L.P. Queiroz 3973 (HRB, HUEFS); Morro do Chapéu, fazenda Boa Esperança,

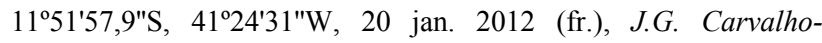
Sobrinho 3270 (HUEFS); Palmeiras, 12²6'17"S, 41 ${ }^{\circ} 30^{\prime} 53^{\prime \prime} \mathrm{W}, 30$ out. 2010 (fl.), S.P.S. Neves 278 (HUEFS); Paraguaçu, 28 abr. 2001 (fr.), D.M. Loureiro 206 (ALCB, MBM); Pindobaçu, 1057'S, 402 $7^{\prime} \mathrm{W}, 3$ set. 1981 (fr.), J.D.C. Arouck Ferreira 82 (CEPEC, HUEFS); Santa Brígida, Raso da Catarina, 09³4'59"S, 38²9'29" W, 28 jun. 2002 (fr.), L.P. Queiroz 7287 (HUEFS).

A espécie é reconhecida com facilidade pelo fruto torcido e moniliforme, com valvas cartáceas. Suas inflorescências, que eram desconhecidas até aqui, permitem inseri-la no grupo com flores heteromórficas. Além disso, percebeu-se uma semelhança entre as brácteas dessa espécie e as de $C$. acacioides. As folhas de $C$. extortum são distintas entre os períodos de floração e frutificação: no primeiro caso, estão em desenvolvimento, jovens e menores; no segundo, estão totalmente desenvolvidas e maiores.

2.4. Chloroleucon foliolosum (Benth.) G.P.Lewis, Legumes Bahia: 166. 1987. Pithecolobium foliolosum Benth., London J. Bot. 3: 223. 1844.

Figuras. 11, 12 e 15E,G.

Nomes populares: arapiraca, tatarema (Barneby \& Grimes 1996).

Arbustos ou árvores 1,5-8 m alt., ramos armados. Estípulas $3,5-5 \times 1,5-1,8 \mathrm{~mm}$, membranáceas, oblanceoladas. Folhas se expandindo antes e durante a floração; pecíolo 0,5-2,2 cm compr.; raque 2,3-8,2 cm compr.; nectários peciolares a 3-12 mm da base do pecíolo, sésseis ou estipitados, nectários adicionais geralmente na base do último par de pinas; pinas (4)5-8 pares, 1,3-4,5 cm compr.; folíolos 15-28 pares, 2,5-8 $\times$ 0,7-2 mm, oblongos, ápice cuneado, base obliquamente obtusa, membranáceos, raramente discolores, pilosos a pubescentes. Glomérulos heteromórficos, pedúnculo 0,8-2 cm compr., brácteas 1-1,2 mm compr., lineares. Flores periféricas subsésseis; cálice 1-1,5 mm compr.; corola 2,9-5,2 mm compr.; filetes 10-15, 5,5-16,3 mm compr., livres por 3,5-12,5 mm compr.; ovário 1-1,9 mm compr., cilíndrico, estilete 8,5-13,5 mm compr. Flores centrais sésseis; cálice $0,9-1,5 \mathrm{~mm}$ compr.; corola 3,1-6 mm compr.; filetes 10-20, 5,5-13,6 mm compr., livres por 1,5-6,5 mm compr.; ovário 1-1,5 mm compr., cilíndrico, estilete 8-10,1 mm compr. Frutos 8$15,5 \times 1,1-1,9 \mathrm{~cm}$, geralmente sésseis, falcados, ápice obtuso a arredondado, base atenuada, margens não

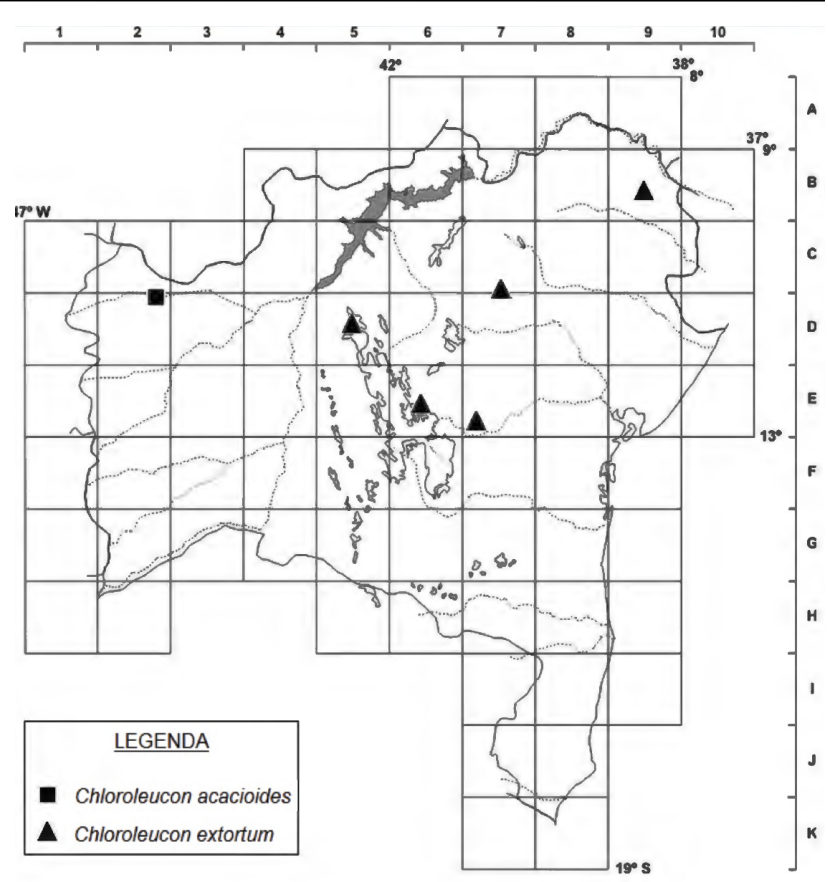

Figura 9. Distribuição geográfica de Chloroleucon acacioides e C. extortum no estado da Bahia.

moniliformes; valvas constritas entre as sementes, carnosas, raramente papiráceas (frutos imaturos). Sementes ca. $6,5 \times$ ca. $4 \times 3,5 \mathrm{~mm}$; testa marrom, pleurogramas em forma de U.

Ocorre no Chaco da Bolívia, Argentina e no Brasil (Ceará, Pernambuco, Rio Grande do Norte, Bahia, Sergipe, Paraíba, Paraná, Piauí, Mato Grosso do Sul; Barneby \& Grimes 1996; contrastando com Iganci 2013, que registra a espécie apenas para o Pará). Amplamente distribuída na Bahia. B4, B5, B8, B9, C7, C8, D3, D5, D6, D7, E3, E7, F3, F4, F5, F6, F7, G6, H8: Caatinga. Floração: agosto a novembro; frutificação: março e outubro.

Material selecionado -Abaíra, estrada Ouro Verde-Funil, ca. 4 km de Ouro Verde, $13^{\circ} 20^{\prime}$ S, $41^{\circ} 45^{\prime} \mathrm{W}, 19$ set. 1992 (fl.), W. Ganev 1123 (CEPEC, HUEFS); Boa Vista do Tupim, estrada de Baixio para a balsa pequena, $15 \mathrm{~km}$ de Baixio, 20 fev. 2013 (est.), P.G.C.

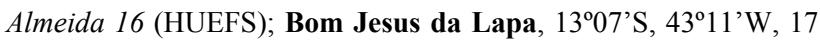
abr. 1980 (fr.), R.M. Harley 21458 (CEPEC); Brotas de Macaúbas,

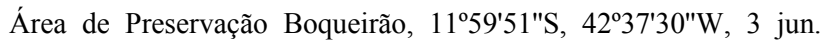
2007 (fr.), A.A. Conceição 2221 (HUEFS); Caculé, Km 43 da estrada Brumado-Caetité, 14 abr. 1983 (fr.), A.M. Carvalho 1700 (CEPEC, HUEFS, RB); Cafarnaum, ca. $20 \mathrm{~km}$ a noroeste de Segredo na BR-122, em direção a Cafarnaum, $11^{\circ} 51^{\prime} \mathrm{S}, 41^{\circ} 36^{\prime} \mathrm{W}, 24$ jul. 1993 (fr.), L.P. Queiroz 3423 (CEPEC, HUEFS, MBM); Campo Alegre de Lourdes, Morro do Tuiuiu, 09 $29^{\prime} 01^{\prime \prime} \mathrm{S}$, 4305'21"W, 25 nov. 2003 (est.), L.P. Queiroz 7951 (HUEFS); Canudos, Estação Biológica de Canudos, 0956'34"S, 3859'19"W, 27 jun. 2002 (fr.), L.P. Queiroz 7205 (HUEFS); Caturama. $13^{\circ} 17^{\prime} 27^{\prime \prime S}, 42^{\circ} 13^{\prime} 32^{\prime \prime W}, 5$ jul. 2007 (est.), A.A. Conceição 2386 (HUEFS); Curaçá, estrada Curaçá-Uauá, Km 34, 09²0'S, 3952'W, 29 maio 1985 (fr.), G. Fotius 4036 (HUEFS); Feira de Santana, Socorro, 23 mar. 2001 (est.), J. Cerqueira 6 (HUEFS); Glória, Raso da Catarina, 09 $20^{\prime} \mathrm{S}, 39^{\circ} 29^{\prime \prime} \mathrm{W}, 6$ jun. 2004 (fr.), M.V.M. Oliveira 710 (HUEFS); Ibiracoara, 13³0'26"S, 41³2'50"W, 23 jun. 1978 


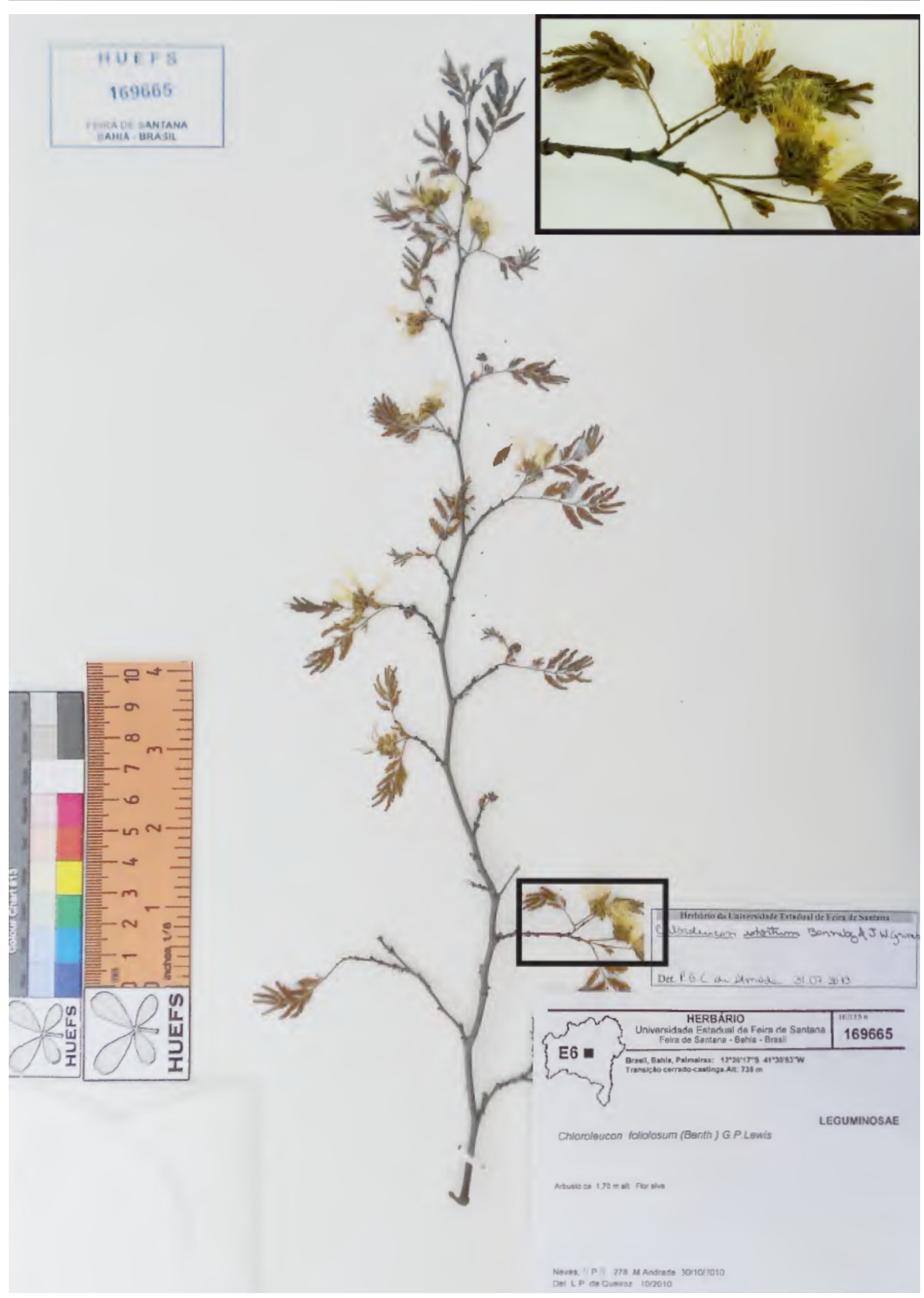

Figura 10. Chloroleucon extortum: destaque para inflorescência (Neves 278). 


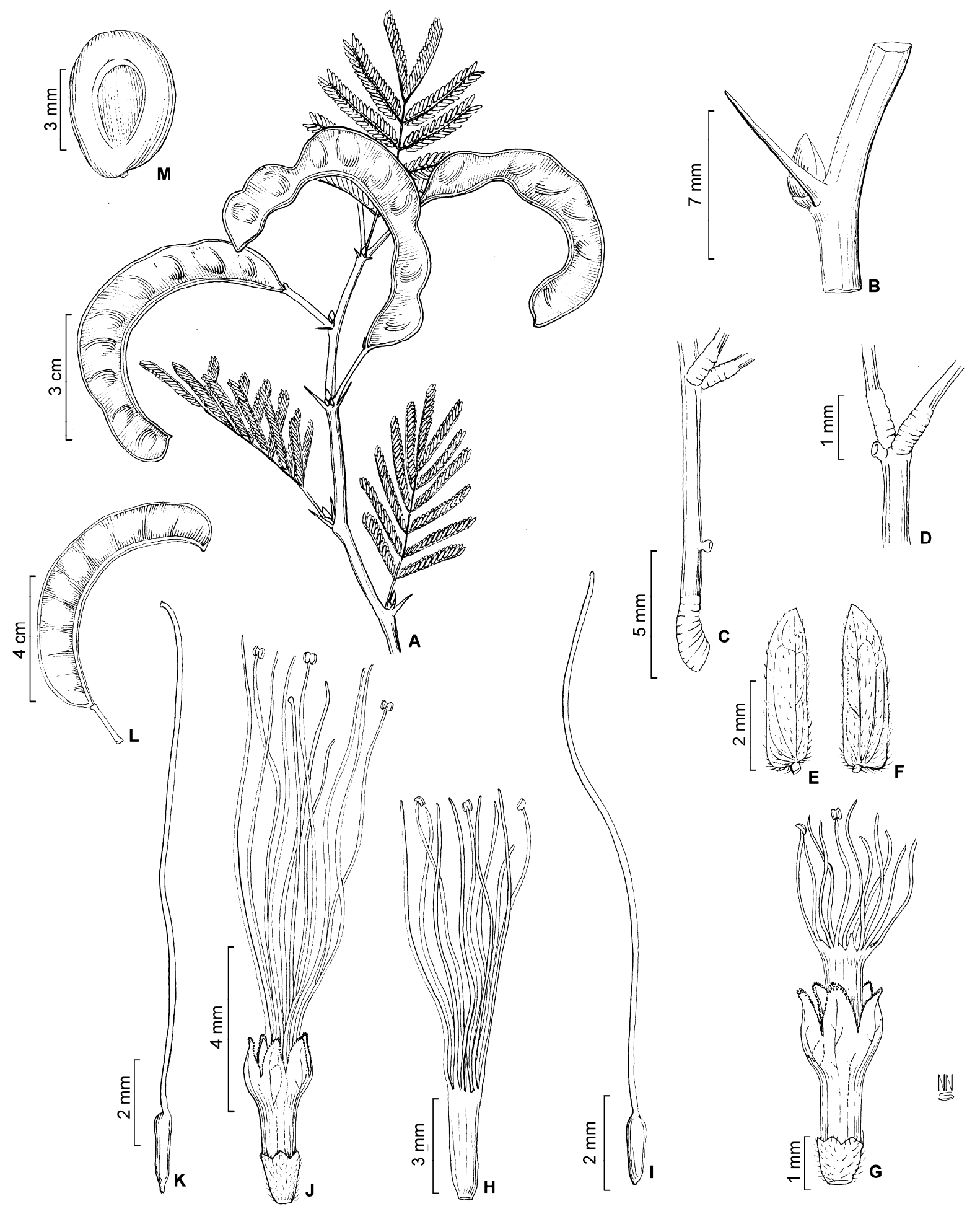

Figura 11. Chloroleucon foliolosum: A- ramos com frutos; B- espinho e gema; C- nectário peciolar; D- nectário adicional (base do último par de pinas); E- folíolo (face adaxial); F- folíolo (face abaxial); G- flor central; H- androceu (flor periférica); I- gineceu (flor central); J- flor periférica; K- gineceu (flor periférica); L- fruto; M- semente. (A- Miranda 832; B-K- Harley 54647)

(fr.), A. Araújo 33 (RB); Ibipeba, $52 \mathrm{~km}$ de Ibipeba, $11^{\circ} 17^{\prime} \mathrm{S}$, 42 $12^{\prime} \mathrm{W}, 23$ nov. 2005 (fl.), A.C. Melo 5 (HUEFS); Igaporá, fazenda Malhada de Joazeiro, 15 out. 1985 (fl., fr.), E.L.P.G. Oliveira 727 (IPA); Iramaia, rodovia Maracás-Contendas do Sincorá, $33 \mathrm{~km}$ sudoeste de Maracás, $4 \mathrm{~km}$ após povoado Pé de
Serra, 13³5'S, 4040’W, 23 mar. 1988 (fr.), S. Ginzbarg 856 (CEPEC); Irecê, Barra do Mendes, caminho para Ipupiara,

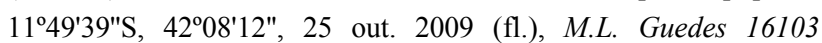
(ALCB, HUEFS, MBM); Itaju, rodovia Palmira-Itaju, 14 out. 1967 (fl.), R.S. Pinheiro 281 (CEPEC); Jaguarari, fazenda Sítio do 


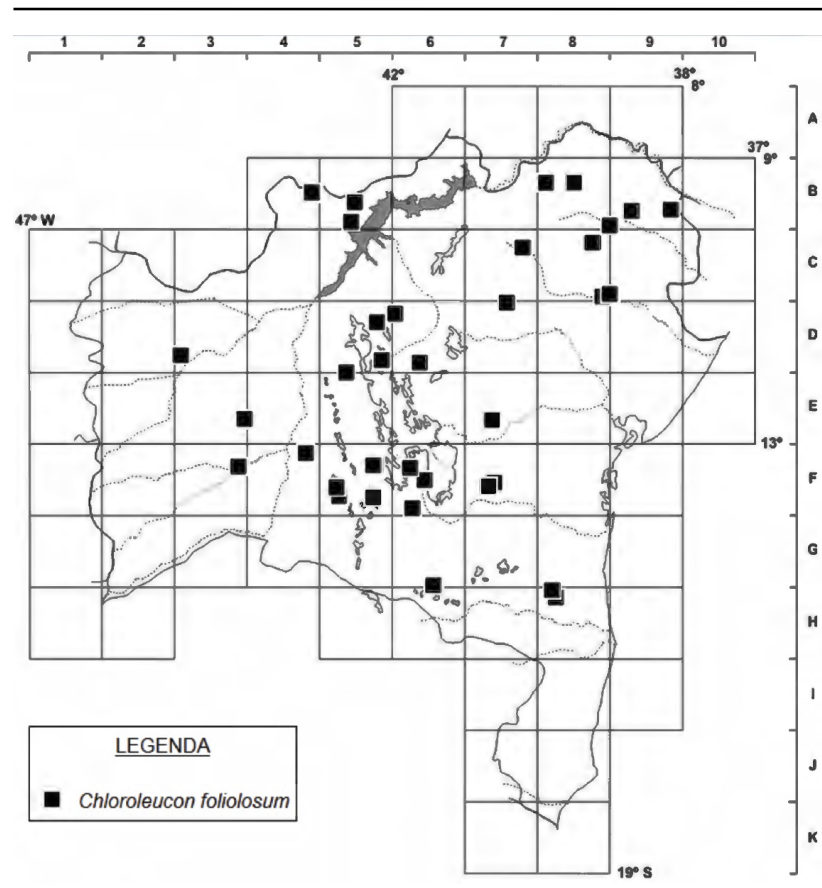

Figura 12. Distribuição geográfica de Chloroleucon foliolosum no estado da Bahia.

Meio, 22 set. 1971(fl.), F.B. Ramalho 11 (IPA); Jequié. Km 36 da estrada de Jequié-Contendas do Sincorá, 12 out. 1983 (fl.), A.M. Carvalho 1939 (HUEFS, CEPEC); Jeremoabo, Raso da Catarina, 15 maio 1981 (fr.), G. Pinto 106 (HUEFS, CEPEC); Livramento do Brumado, 135' $\mathrm{S}, 41^{\circ} 43^{\prime} \mathrm{W}, 10$ abr. 1991 (fr.), G.P. Lewis \& S.M.M. Andrade 1972 (CEPEC, MBM, RB); 7 km de Macambo, na estrada para Maniacu, $13^{\circ} 43^{\prime} 48^{\prime \prime} \mathrm{S}, 42^{\circ} 15^{\prime} 35^{\prime \prime} \mathrm{W}, 26$ ago. 2010 (fl.), R.M. Harley 56116 (HUEFS); Maracás, fazenda Tanquinho, ca. 10 $\mathrm{km}$ norte de Maracás, na estrada para Planaltinho, 13³1'30"S, 40³4'20"W, 14 abr. 2007 (fr.), L.P. Queiroz 13031 (HUEFS); Monte Santo, fazenda Bom Jesus, 10 10'51"S, 39¹3'44"W, 11 out. 2000 (fr.), C.M.L. Aguiar 7 (HUEFS); Morro do Chapéu, ca. 2 km da comunidade Gruta dos Brejões, $11^{\circ} 00^{\prime} 53^{\prime \prime S}, 40^{\circ} 24^{\prime} 19^{\prime \prime} \mathrm{W}, 4$ maio 2007 (est.), D. Cardoso 1835 (HUEFS); Paramirim, caminho Catuarama para Mateus, 1317'50"S, 42 14'44", 28 abr. 2007 (fr.), A.A. Conceição 1919 (CEPEC, HUEFS); Paulo Afonso, Raso da Catarina, $09^{\circ} 43^{\prime} 53^{\prime \prime} \mathrm{S}, \quad 38^{\circ} 40^{\prime} 59^{\prime \prime} \mathrm{W}, 20$ set. 2008 (fr.), A.A. Conceição 3001(HUEFS); Pedra Branca, complexo Itaparica, 2 jul. 2003 (fr.), M. Oliveira 2475 (RB); Pilão Arcado, Estrada de Espinheiro, $09^{\circ} 53^{\prime} \mathrm{S}, 42^{\circ} 33^{\prime} \mathrm{W}, 29$ fev. 2000 (est.), T. Ribeiro 75 (HUEFS, RB, SPF); Quijingue, Serra das Candeias, ca. $5 \mathrm{~km} \mathrm{a}$ oeste do povoado Quixaba do Mandacaru, no limite com o Município de Tucano, 10 55'20"S, 3904'59"W, 8 jul. 2006 (fr.), D. Cardoso 1319 (HUEFS); Remanso, estrada para Pilão Arcado, entrada à direita, ca. $29 \mathrm{~km}$ da cidade, $09^{\circ} 45^{\prime} 18^{\prime \prime} \mathrm{S}, 42^{\circ} 18^{\prime} 10^{\prime \prime} \mathrm{W}, 16$ jun. 2001 (fr.), T.S. Nunes 480 (ALCB, CEPEC, HRB, HUEFS); Riachão das Neves, 1912 (fr.) L. Zehntner 4031 (IPA); Rio de Contas, estrada Rio de Contas-Jussiape, 9 km, 13⒊ $36^{\prime} 10^{\prime \prime S}$, 4245'45"W, 23 maio 2004 (fr.), G. Pereira-Silva 9119 (HUEFS); Santa Brígida, fazenda do Sr. José Alves, 0942'51"S, 38 $8^{\prime} 44^{\prime \prime W}$, 28 nov. 2009 (fl.), E. Melo 7258 (HUEFS); Santa Cruz da Vitória, fazenda Boa Fé, 9,3 km da rodovia para Itaju do Colônia, $15^{\circ} 02^{\prime} 24^{\prime \prime S}, 39^{\circ} 47^{\prime} 10^{\prime \prime W}, 18$ abr. 2006 (fr.), M.M.M. Lopes 646 (HUEFS, RB); Santa Maria da Vitória, morro da torre de telefonia, 131' $18^{\prime} 13^{\prime} \mathrm{S}, 4^{\circ} 06^{\prime} 55^{\prime \prime} \mathrm{W}, 17$ fev. 2000 (fl.), L.P. Queiroz 6118 (ALCB, CEPEC, HUEFS); São Gabriel, estrada para Jussara, $11^{\circ} 09^{\prime} 54$ "S, 41 ${ }^{\circ} 56^{\prime} 34^{\prime \prime W}, 25$ out. 2009 (fl.), E. Melo 6943 (ALCB, HUEFS); Tabocas, $5 \mathrm{~km}$ para o norte de Tabocas, Chapadão Ocidental da Bahia, 12 $32^{\prime} \mathrm{S}, 44^{\circ} 02^{\prime} \mathrm{W}, 1$ maio 1980 (fr.), R.M. Harley 22007 (CEPEC, IPA, RB); Tremedal, $43 \mathrm{~km}$ de Tremedal e Piripa, 15 out. 1970 (fl.), D. Andrade-Lima 6053 (IPA); Tucano, povoado Bizamum, ca. $23 \mathrm{~km}$ de Tucano, 10 $0^{\circ} 53^{\prime} 39^{\prime \prime} \mathrm{S}, 38^{\circ} 58^{\prime} 40^{\prime \prime} \mathrm{W}$, 10 jul. 2004 (fr.), D. Cardoso 134 (HUEFS, IPA).

A espécie difere das demais na Bahia principalmente pela forma do fruto, que é falcado. Em relação aos caracteres foliares (número de pinas e/ou número de folíolos), mostra grande sobreposição com outras espécies, como $C$. extortum, $C$. acacioides e $C$. dumosum.

2.5. Chloroleucon tortum (Mart.) Pittier ex Barneby \& J.W. Grimes, Mem. New York Bot. Gard. 74(1): 146. 1996. Pithecolobium tortum Mart., Flora 20(2): Beibl. 114. 1837.

Figuras 13, 14 e 15A-D,F,H.

Nomes populares: angico-branco, jacaré, jurema, tataré, vinhático-de-espinho (Barneby \& Grimes 1996).

Árvores, 3,5-5 m alt., ramos com espinhos ou inermes. Estípulas 5-9 × 0,7-1 mm, membranáceas, oblanceoladas. Folhas totalmente desenvolvidas durante a floração; pecíolo 0,5-2,2 cm compr.; raque 2-6,7 cm compr.; nectários peciolares a 3-9 $\mathrm{mm}$ da base do pecíolo, sésseis ou estipitados, nectários adicionais na raque, geralmente entre o último par de pinas; pinas 3 ou 4 pares, 1,9-4,9 cm compr.; folíolos 6-8 pares, 10-19 × 4,5-10 mm, oblongos a obovados, ápice obtuso a arredondado, base obtusa, cartáceos, glabros ou pilosos. Glomérulos heteromórficos, pedúnculo 0,6-1,8 cm compr., brácteas 0,2-1 $\mathrm{mm}$ compr., lineares. Flores periféricas subsésseis; cálice 1,7-2,5 mm compr.; corola 5,5-6 mm compr.; filetes 12-14, 15,5-20 mm compr., livres por 11-15 mm compr.; ovário 1,3-2,1 $\mathrm{mm}$ compr., cilíndrico, estilete 11-16 mm compr. Flores centrais sésseis; cálice 2,1-2,4 mm compr.; corola 5,3-6,5 mm compr.; filetes 11-13, 8,6-15,5 mm compr., livres por 1,3-6,5 mm compr.; ovário 1,2-1,5 mm compr., séssil, cilíndrico, estilete 12$12,5 \mathrm{~mm}$ compr. Frutos $14-21 \times 1-1,5 \mathrm{~cm}$, sésseis, espiralados, compressos, não moniliformes, ápice obtuso a arredondado, base atenuada, margens não moniliformes; valvas constritas entre as sementes, cartáceas (frutos imaturos) a carnosas (maduros). Sementes $5-6,5 \times 4,5-5,5 \times$ ca. 2,2 $\mathrm{mm}$; testa marrom, pleurograma em forma de $U$.

Endêmica do Brasil (Tocantins, Bahia, Minas Gerais, Espírito Santo, Rio de Janeiro e São Paulo; Barneby \& Grimes 1996; Iganci 2013). E7, E9: Caatinga. Floração: outubro a junho; frutificação: março a setembro. 


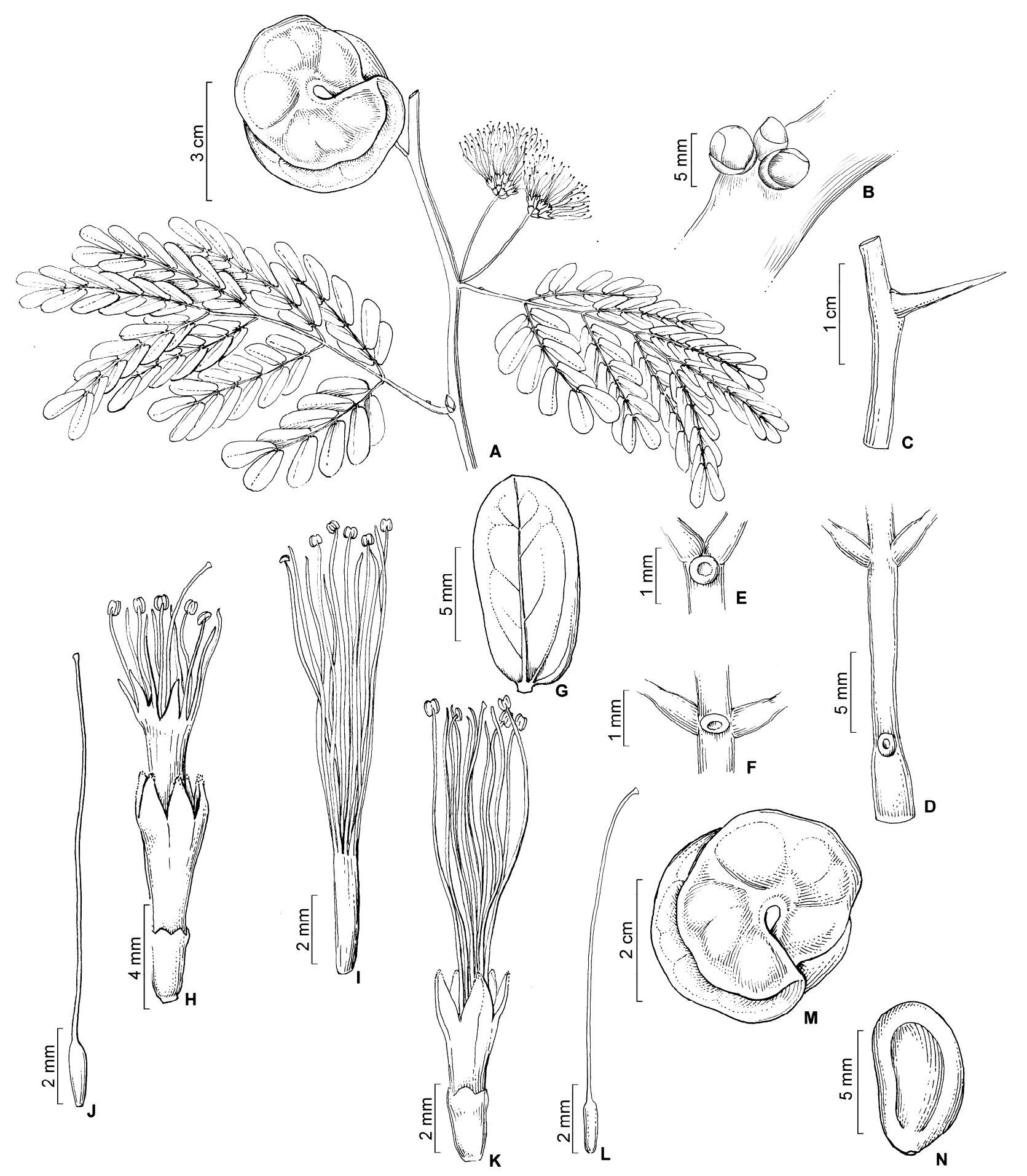

Figura 13. Chloroleucon tortum: A- ramo com inflorescências e fruto; B- gemas; C- espinho; D- nectário peciolar; E- nectários adicionais na raque, entre o último par de pinas; F- nectários adicionais na raque, entre penúltimo par de pinas; G- folíolo (face adaxial); H- flor central; I- androceu (flor periférica); J- gineceu (flor central); K- flor periférica; L- gineceu (flor periférica); M- fruto; N- semente. (A, M- Dutra 70; B-L- Queiroz 7624; N- Johnson 2552-82)

Material selecionado - Boa Vista do Tupim, fazenda Arizona, 30 jul. 1995 (fl., fr.), E.A. Dutra 70 (HUEFS); Salvador, Dique do Tororó, $12^{\circ} 56^{\prime} \mathrm{S}, 38^{\circ} 21^{\prime} \mathrm{W}, 11$ mar. 2003 (fl.), L.P. Queiroz 7624 (HUEFS).
Material adicional - BRASIL. RIO DE JANEIRO: Rio de Janeiro, Praia do Flamengo, 4 ago. 1982 (fr.), C.D. Johnson 2552 (EAC, NYBG); Cabo Frio, loteamento atrás do Condomínio Bosque do Peró, 20 jun. 1997 (fr.), P.R. Farág 406 (RB). 


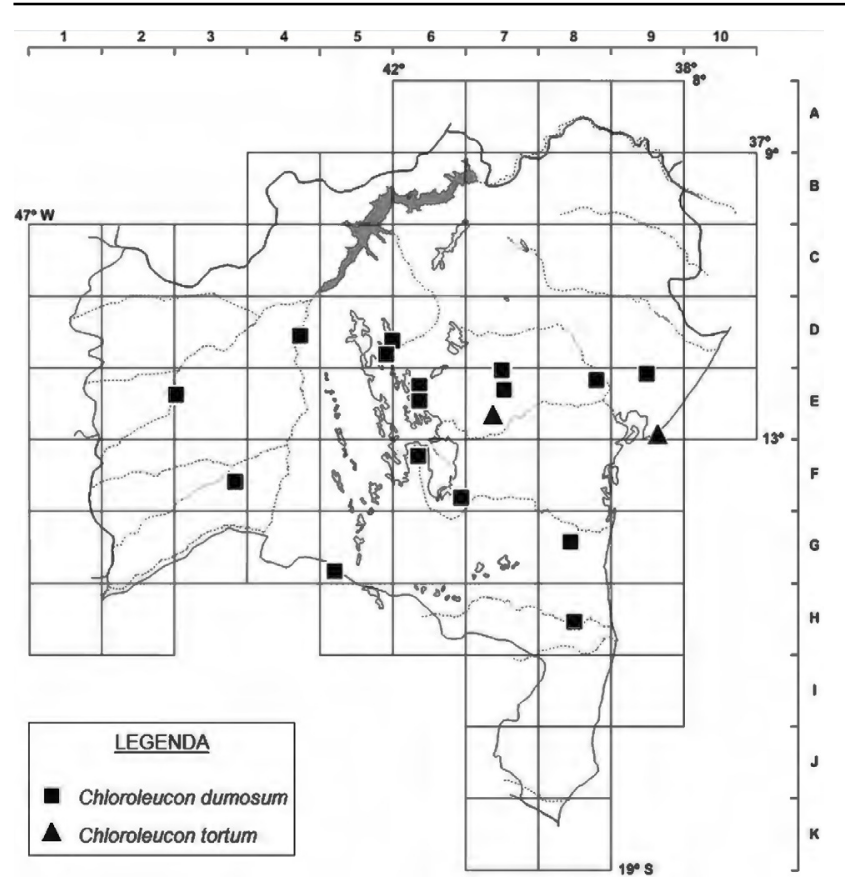

Figura 14. Distribuição geográfica de Chloroleucon dumosum e $C$. tortum no estado da Bahia.

A espécie é facilmente reconhecida pelo número reduzido de folíolos, assim como a forma oblonga a obovada dos folíolos, mas principalmente pelos frutos espiralados e compressos. Está na lista de plantas ameaçadas (World Conservation Monitoring Centre 1998) e, na Bahia, é conhecida por apenas dois espécimes, um deles sabidamente cultivado, o que coloca em dúvida sua ocorrência natural no estado.

\section{Leucochloron Barneby \& J.W.Grimes}

Árvores inermes. Estípulas caducas. Folhas geralmente se expandindo durante a floração; nectários peciolares sésseis; nectários adicionais ausentes ou presentes na base do último e do penúltimo par de pinas; parafilídios presentes; folíolos pinado-palmados, oblongos, indumentados. Glomérulos globosos, fasciculados, nos ramos abaixo das folhas, homomórficos, brácteas caducas. Flores sésseis; cálice cilíndrico, lacínias cuneadas; corola infudibuliforme a campanulada, lacínias agudas; tubo estaminal incluso ou exserto à corola, filetes $32-51$; nectário floral ausente; ovário séssil a estipitado. Fruto folículo ou legume, deiscente, linear, reto a falcado, planocompresso; valvas cartáceas, indumentadas. Sementes orbiculares, compressas, margem hialina; testa rugosa, óssea e translúcida, sem pleurograma.

Leucochloron distribui-se nas Florestas Tropicais Sazonalmente Secas (sensu Pennington et al. 2000), principalmente em florestas semidecíduas, corroborando os dados de Barneby \& Grimes (1996). $\mathrm{O}$ gênero é reconhecido pela presença de parafilídios, gemas peruladas e frutos indumentados. As espécies com ocorrência na Bahia podem ser facilmente diferenciadas pelas folhas (número de pinas e forma dos folíolos), comprimento do tubo estaminal e pelo tipo de fruto.

\section{Chave para as espécies}

1. Folhas com 6-9 pares de pinas; nectários adicionais na raque, no último par de pinas e, na maioria das vezes, também no penúltimo; folíolos com ápice obtuso; filetes 45-51; fruto folículo ... 3.1. L. limae

1'. Folhas com 3-5 pares de pinas; nectários adicionais ausentes; folíolos com ápice agudo; filetes 30-40; fruto legume

3.2. L. minarum

\subsection{Leucochloron limae Barneby \& J.W.Grimes,} Mem. New York Bot. Gard. 74(1): 132. 1996.

Figuras 16, 17 e 19.

Arbustos ou árvores, 3-7 m alt. Estípulas 1,2-3 $\times 0,5-1,5 \mathrm{~mm}$, triangulares, caducas. Folhas se expandindo durante a floração; pecíolo $1-1,9 \mathrm{~cm}$ compr.; raque 2,5-4,5 cm compr.; nectários peciolares a $2-6 \mathrm{~mm}$ da base do pecíolo, nectários adicionais na raque, na base do penúltimo e do último par de pinas; pinas 6-9 pares, 3,6-4,6 cm compr.; folíolos 13-20 pares, 5-7 × 2,1-4 mm, transversalmente elípticos, ápice obtuso, base truncada, papiráceos, pubescente a piloso nas margens; parafilídios $0,8-1 \mathrm{~mm}$, lineares ou filiformes, caducos. Glomérulos com pedúnculo 1,2$2,4 \mathrm{~cm}$ compr., brácteas $0,4-0,7 \mathrm{~mm}$ compr., triangulares a largo-oblanceoladas, caducas. Flores com cálice 1,3-2 mm compr.; corola campanulada, $3,2-4,3 \mathrm{~mm}$ compr.; filetes $45-51,7,5-10,7 \mathrm{~mm}$ compr., livres por $3,2-5 \mathrm{~mm}$ compr.; ovário $1-1,1$ $\mathrm{mm}$ compr., cilíndrico, estilete $8,2-10,5 \mathrm{~mm}$ compr. Fruto folículo, ca. $6,7 \times 1,7 \mathrm{~cm}$, estipitado, velutino, plano-compresso, oblongo, reto a levemente falcado, ápice cuspidado, base atenuada, margens levemente onduladas; valvas coriáceas. Sementes ca. 10,5 × $10,5 \times 1 \mathrm{~mm}$, testa amarela.

Endêmica do Brasil (Bahia, Minas Gerais e Espírito Santo), ocorrendo principalmente em florestas decíduas e semidecíduas. E7, F6, G5, H8: Caatinga. Floresce e frutifica principalmente entre os meses de setembro e outubro.

Material selecionado - Itaberaba, 14 set. 1984 (fl.), $G$. Hatschbach 48194 (MBM); Itapetinga, 17 km de Potiraguá, estrada para Itapetinga, $15^{\circ} 27^{\prime} 0^{\prime \prime} \mathrm{S}, 39^{\circ} 55^{\prime} 3^{\prime \prime} \mathrm{W}, 12$ out. 1999 (fl.), B.M. Silva 46 (HUEFS, RB); Licínio de Almeida, Tigre, 24 out. 2001 (fr.), S.M. Faria 2232 (RB); Livramento do Brumado, $19 \mathrm{~km}$ ao sul de Livramento do Brumado, 9 set. 1994 (fl., fr.), A.M. Carvalho 5339 (CEPEC, RB); Santa Brígida, Raso da Catarina, 09³4'59"S, 38'29'29"W, 28 jun. 2002 (fr.), L.P. Queiroz 7287 (HUEFS); Serra Preta, BA-052 a 35 km de Ipirá, 7 set. 1990 (fr.), H.C. Lima 3877 (NY).

A espécie pode ser reconhecida por apresentar mais pinas e nectários adicionais no ultimo par de pinas. Suas flores apresentam tubo estaminal com comprimento igual ou levemente maior que a corola e os frutos são do 
tipo folículo. Leucochloron limae tem poucos registros e está na lista de espécies ameaçadas (World Conservation Monitoring Centre 1998).

\subsection{Leucochloron minarum (Glaz. ex Harms)} Barneby \& J.W.Grimes, Mem. New York Bot. Gard. 74(1): 135. 1996. Pithecellobium minarum Glaz. ex Harms, Repert. Spec. Nov. Regni Veg. 17: 92. 1921.

\section{Figuras 18 e 19.}

Árvores, 4-20 $\mathrm{m}$ alt. Estípulas 5-7 mm compr., lineares, caducas. Folhas se expandindo antes da floração; pecíolo $1-2 \mathrm{~cm}$ compr.; raque $0,9-4,8 \mathrm{~cm}$ compr.; nectários peciolares a 9-16 $\mathrm{mm}$ da base do pecíolo, nectários adicionais ausentes; pinas 3-5 pares, 3,8-6,5 cm compr., folíolos 15-19 pares, 6-10 × 2,5-5 $\mathrm{mm}$, oblongos, ápice agudo, encurvado, base truncada, papiráceos, pilosos nas margens; parafilídios 0,9-1 mm compr., filiformes, persistentes. Glomérulos com pedúnculo 1,7-3,2 cm compr., brácteas 1,5-2 $\mathrm{mm}$ compr., filiformes, caducas, pubescentes. Flores com cálice 2,3-3,4 $\mathrm{mm}$ compr.; corola infudibuliforme, 4,4-5,2 mm compr.; filetes 30-40, 10-12 mm compr., livres por 5-5,5 mm compr.; ovário séssil, cilíndrico. Fruto legume, 7,5-14,2 × 1,8-2,3 cm, estipitado, velutino, plano-compresso, oblongo, ápice arredondado, base atenuada, margens levemente onduladas; valvas coriáceas. Sementes não vistas.

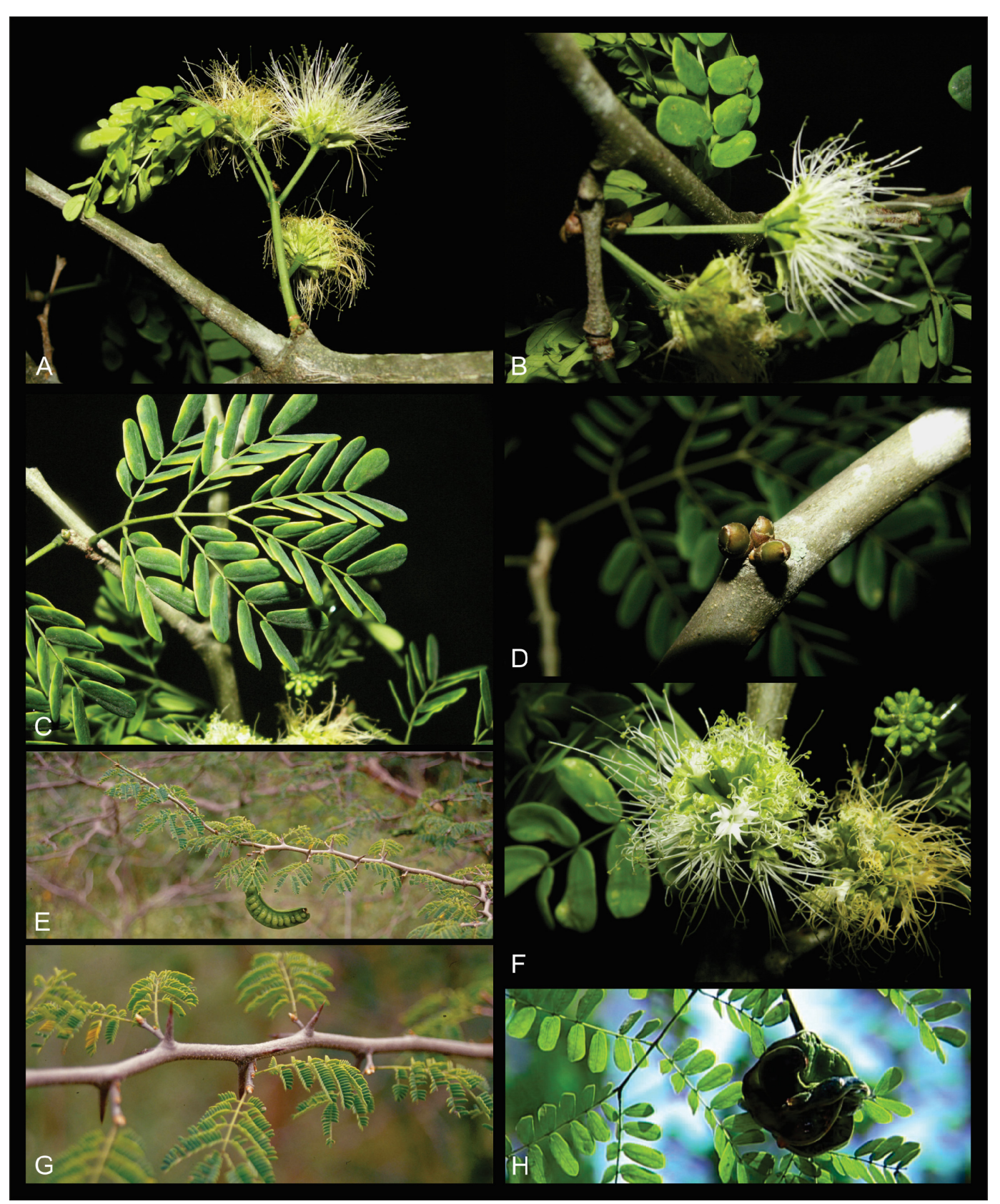

Figura 15. A-D, F, H- Chloroleucon tortum: A, B, F- inflorescência; C- folha; D- gemas; H- fruto. E, G- C. foliolosum: E- hábito e fruto; G- folhas e espinhos. (Fotos: A-D, F- E.R. de Souza; E e G: L.P. Queiroz; H: www.umpedeque.com.br) 


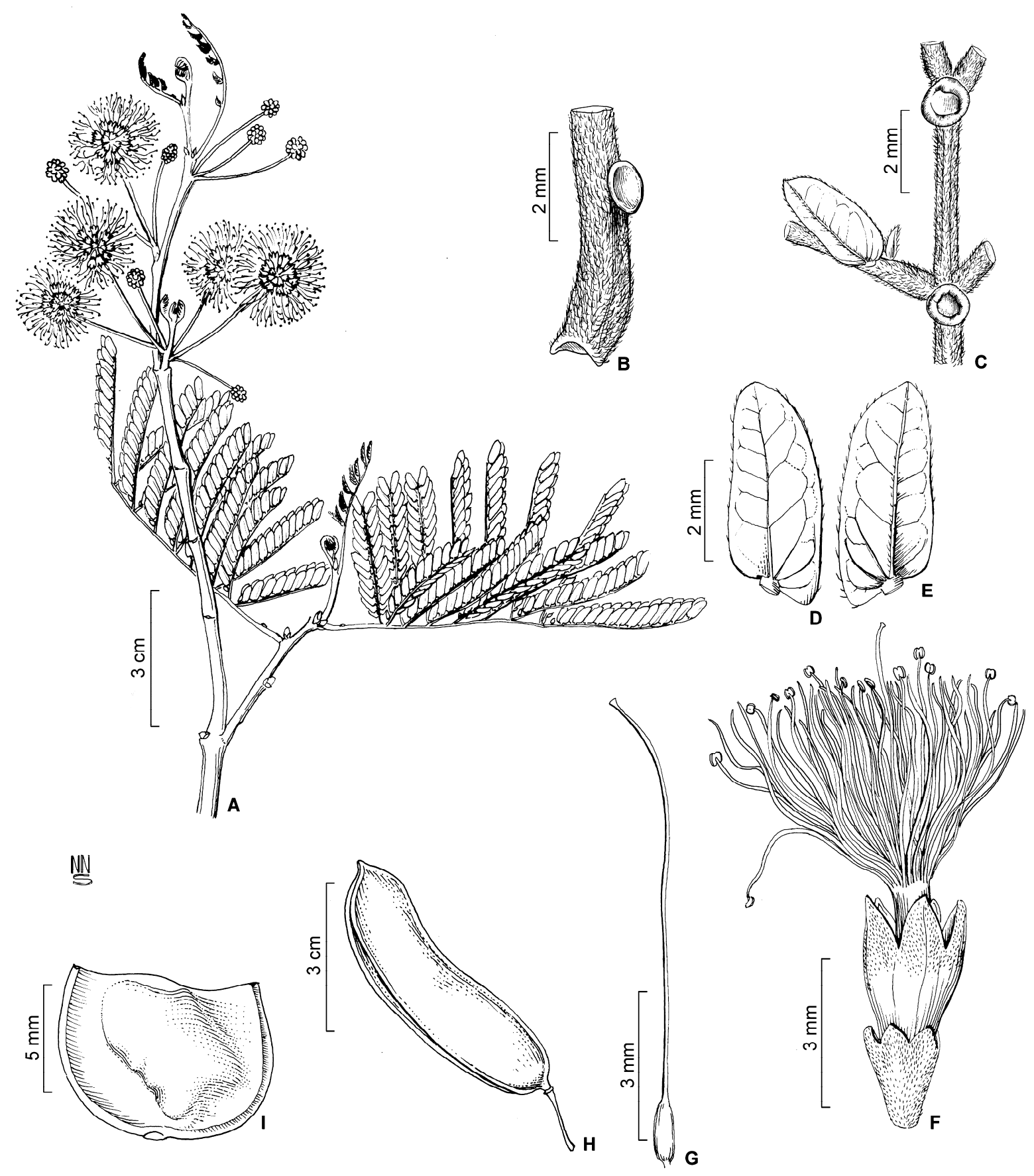

Figura 16. Leucochloron limae: A- ramo com inflorescências; B- nectário peciolar, na base do último par de pinas; C- nectários adicionais, na base do penúltimo par de pinas, e parafilídio; D- folíolo (face adaxial); E- folíolo (face abaxial); F- flor; G- gineceu; H- fruto; I- semente. (Oliveira 1626)

Considerada endêmica de Minas Gerais (Barneby \& Grimes 1996), foi registrada também para o sudoeste da Bahia. F3: Caatinga. Floração: outubro (Barneby \& Grimes 1996); frutificação: março e abril.

Material examinado - Coribe, ca. $5 \mathrm{~km}$ ao sul, em estrada de terra que cruza pequeno ramal a $5.1 \mathrm{~km}$ leste de Ponto d'Água, a 24,4 km sul de São Felix do Coribe, na estrada para Coribe, 1335'10"S, 44¹9'12"W, 11 abr. 2007 (fr.), L.P. Queiroz 12780 (HUEFS).

Material adicional - BRASIL. MINAS GERAIS: Engenheiro Dolabella, Montes Claros, 8 mar. 1929 (fr.), J.G. Kuhlmann 74 (RB); Santo Hipólito, estrada Corinto-Conselheiro, $18^{\circ} 17$ 'S,

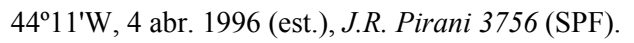

A espécie pode ser reconhecida pelo pequeno número de pinas, ausência de nectários adicionais entre os pares de pinas, flores com menos estames e tubo estaminal notadamente exserto à corola e fruto do tipo legume. Os dados relativos às flores foram retirados da revisão mais recente envolvendo $L$. minarum (Barneby \& Grimes 1996), já que não foram examinados materiais com flor dessa espécie. É uma espécie pouco coletada e corre risco de extinção (World Conservation Monitoring Centre 1998). 


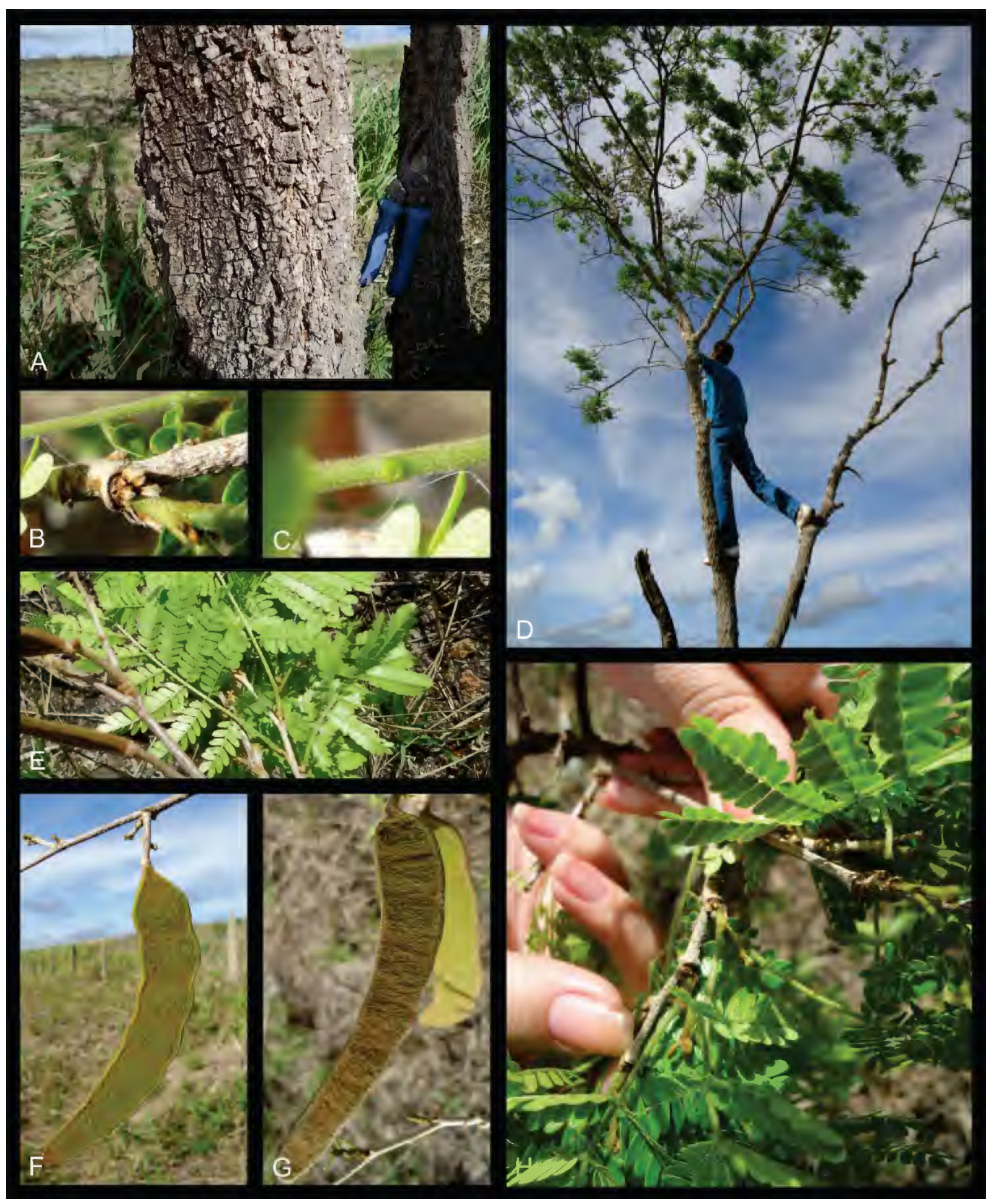

Figura 17. Leucochloron limae: A- tronco; B- gemas; C- nectário peciolar; D- hábito; E, H- folhas; F, G- frutos. (Fotos: L. Rocha)

\section{AGRADECIMENTOS}

À CAPES (projeto PROTAX) e CNPq (projeto SISBIOTA), pelas bolsas concedidas durante o desenvolvimento do trabalho; ao PPGBot-UEFS, pela infraestrutura; ao Programa de Pesquisa em Biodiversidade do Semiárido (PPBio Semiárido $\mathrm{MCT} / \mathrm{CNPq}$ ), ao Sistema Nacional de Pesquisa em
Biodiversidade (SISBIOTA - CNPq 563084/2010-3 e FAPESB PES0053/2011) e CAPES (PNPD $\mathrm{n}^{\circ}$ 02697/09-2) pelo suporte financeiro; aos colegas e funcionários do HUEFS, pelo auxílio em diversas fases do trabalho; aos curadores e funcionários dos herbários visitados pela recepção e empréstimo de materiais; a Natanael Nascimento Santos pelas ilustrações botânicas. 


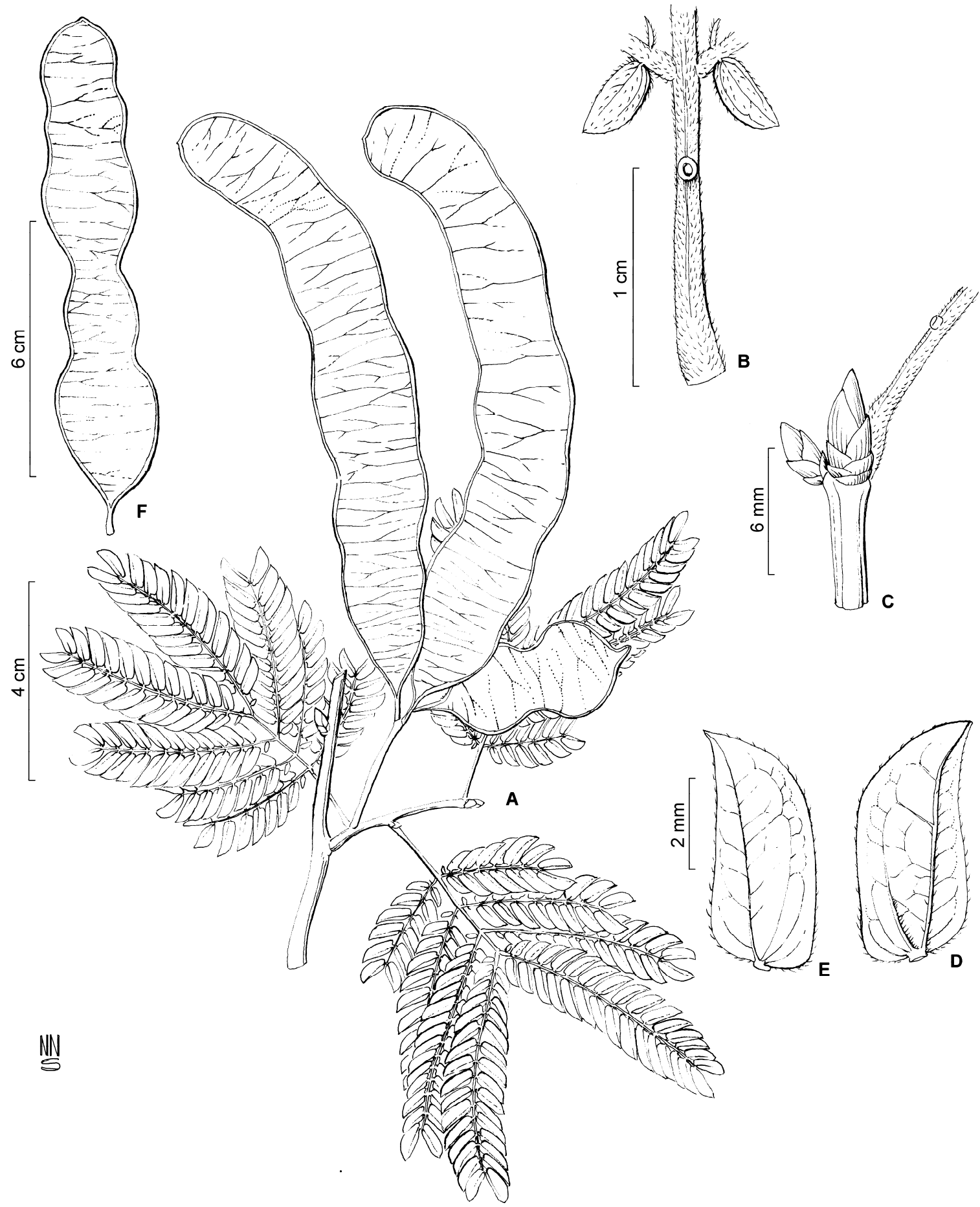

Figura 18. Leucochloron minarum: A- ramo com frutos; B- nectário peciolar e parafilídios; C- gemas; D- folíolo, face abaxial; E- folíolo (face adaxial); F- fruto (Queiroz 12780).

\section{REFERÊNCIAS}

Barneby, R.C. \& Grimes, J.W. 1996. Silk tree, guanacaste, monkey's earring: a generic system for the synandrous Mimosaceae of the Americas, Part I. Abarema, Albizia, and allies. Memoirs of the New York Botanical Garden 74: (1): 126157.

Iganci, J.R.V. Chloroleucon. In: Lista de Espécies da Flora do Brasil. Jardim Botânico do Rio de Janeiro. Disponível em
http://floradobrasil.jbrj.gov.br/jabot/floradobrasil/FB22878; acesso em 13 out. 2014.

Lewis, G.P. \& Rico Arce, L. 2005. Tribe Ingeae. In: G. Lewis, B. Schrire, B. Mackinder \& M. Lock (eds), Legumes of the World. Royal Botanic Gardens, Kew, p. 193-195.

Lima, H.C.; Queiroz, L.P.; Morim, M.P.; Souza, V.C.; Dutra, V.F.; Bortoluzzi, R.L.C.; Iganci, J.R.V.; Fortunato, R.H.; Vaz, A.M.S.F.; Souza, E.R.; Filardi, F.L.R.; Valls, J.F.M.; Garcia, F.C.P.; Fernandes, J.M.; Martins-da-Silva, R.C.V.; 


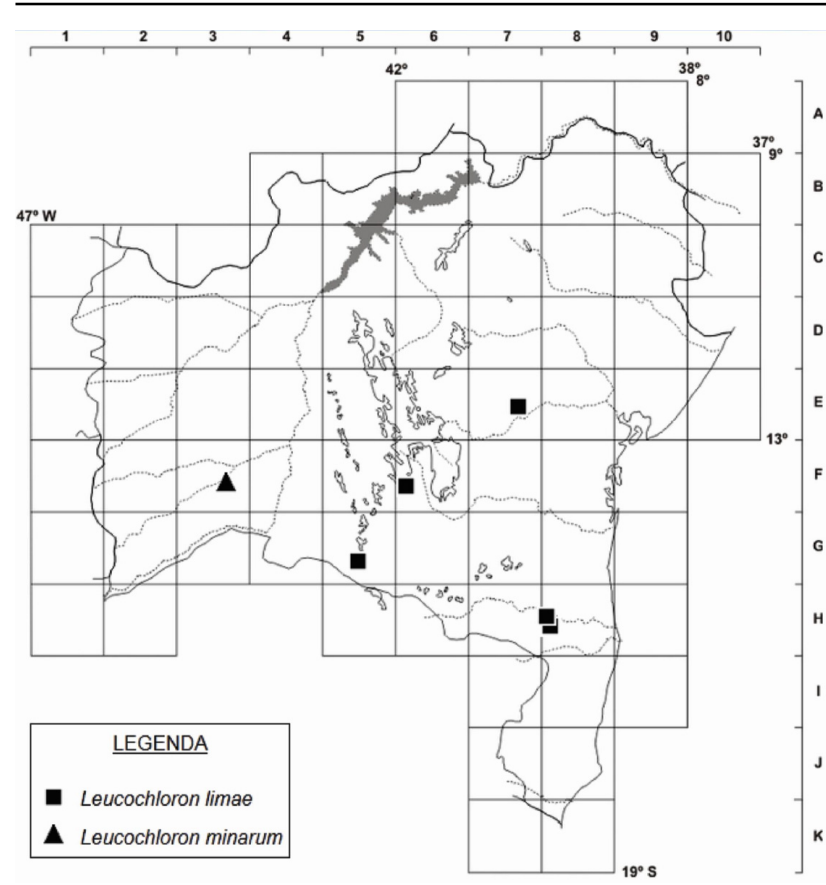

Figura 19. Distribuição geográfica de Leucochloron limae e L. minarum no estado da Bahia.
Perez, A.P.F.; Mansano, V.F.; Miotto, S.T.S.; Tozzi, A.M.G.A.; Meireles, J.E.; Lima, L.C.P. ; Oliveira, M.L.A.A.; Flores, A.S.; Torke, B.M.; Pinto, R.B.; Lewis, G.P.; Barros, M.J.F.; Schütz, R.; Pennington, T.; Klitgaard, B.B.; Rando, J.G.; Scalon, V.R.; Cardoso, D.B.O.S.; Costa, L.C.; Silva, M.J.; Moura, T.M.; Barros, L.A.V.; Silva, M.C.R.; Queiroz, R.T.; Sartori, A.L.B.; Camargo, R.A. \& Lima, I.B. 2013. Fabaceae. In: Lista de Espécies da Flora do Brasil. Jardim Botânico do Rio de Janeiro. Disponível em http://floradobrasil.jbrj.gov.br/jabot/floradobrasil/FB115; acesso em 13 out. 2013.

Queiroz, L.P. 2009. Leguminosas da Caatinga. Universidade Estadual de Feira de Santana, Feira de Santana, p. 220-225.

Queiroz, L.P.; Cardoso, D.B.O.S.; Conceição, A.S.; Souza, E.R.; Tozzi, A.M.G.A.; Pérez, A.P.F.; Silva, M.J.; Simon, M.F.; Mansano, V.F.; Costa, J.A.S.; Rodrigues, W.A.; Lima, L.C.P. \& du Bocage, A. 2009. Leguminosae. In: A.M. Giulietti, A. Rapini, M.J.G. Andrade, L.P. Queiroz \& J.M.C. Silva (orgs), Plantas Raras do Brasil. Conservação Internacional, Belo Horizonte, p. 212-237.

Pennington, R.T.; Prado, D.E. \& Pendry, C.A. 2000. Neotropical seasonally dry forests and Quaternary vegetation changes. Journal of Biogeography 27: 261-273.

World Conservation Monitoring Centre. 1998. In: IUCN 2013. IUCN Red List of Threatened Species. Version 2013.1. Disponível em www.iucnredlist.org; acesso em 19 ago. 2013.

\section{LISTA DE EXSICATAS}

Agra, M.F. 05 (2.1); Aguiar, C.M.L. 7 (2.4); Alencar, M.E. 289 (2.1); Almeida, K. 172 (2.1); Almeida, P.G.C. 8 (2.2), 12 (2.3), 16 (2.4), 17 (3.2); Andrade s.n. JPB 19234 (2.1); Andrade-Lima, D. s.n. IPA 1073, s.n. IPA 1092 (2.2), 458, 699, 1178 (2.4), 1430 (2.1), 6053,6426 (2.4); Annable, C.R. 3776 (2.5); Antunes, M.M. s.n. EAC 18695 (2.1); Araújo, A. 33 (2.4), 106 (2.2); Araújo, A.P. 75 (1.1); Araújo, D. 8882 (2.5); Araújo, F.S. 520, 1048 (2.1); Arouck Ferreira, J.D.C. 82 (2.3); Barbosa, M.R. 1292 (2.4), 2085 (2.1); Bautista, H.P. 1078 (1.1); Blanchet, J.S. 2776 (1.1), 3136 (2.4); Bocage, A. s.n. IPA 73403 (2.4); Cardoso, D. 134, 1319, 1835 (2.4), 1921 (2.2), 2351,2378 (2.1); Carneiro, J. s.n. JPB 2896, s.n. JPB 16588 (2.4); Carvalheira, R.C.P. s.n. JPB 3222 (2.1); Carvalho, A.M. 1700, 1939 (2.4), 5339 (3.1); Carvalho, A.M.M. s.n. EAC 52590 (2.1); Carvalho, D.A. 100 (2.5); Carvalho-Sobrinho, J.G. 2485 (2.4), 3270 (2.3); Castro, A.C.F. 1680 (2.1); Castro, A.S.F. 2259, s.n. EAC 27430 (2.2), s.n. EAC 24577 (2.1); Cavalcanti, A.C.S. 144 (2.5); Collares, J.E.R. 193 (2.4); Conceição, A.A. 1919 (2.4), 1981 (1.1), 2221 (2.4), 2428 (1.1), 2386, 2423 (2.4), 2733 (2.2), 3001 (2.4); Cerqueira, J. 6 (2.4); Costa, R.C. 319 (2.1); Curran, H.M. 28, 59 (2.2); Dionísio, G.O. 330 (2.1); Duarte, A.P. 8566 (1.1); Ducke, A. 17, 1669, 16358 (2.1); Dutra, E.A. 70 (2.5); Edilberto, E. s.n. EAC 44514 (2.1); Emperaire, L. 564 (2.4); Eugênio, J. 588, 600 (2.1); Farág, P.R. 406 (2.5); Faria, S.M. de 2232 (3.1); Farney, C. 2259, 4244 (2.5); Felix, L.P.S s.n. JPB 8419 (2.1); Fernades, A. s.n. EAC 1092, s.n. EAC 14899, s.n. EAC 16878, s.n. EAC 23499, s.n. EAC 25956 (2.1); Fernandes, D. 288 (2.5); Ferreira, E.V.R. 422 (2.4); Ferreira, J.D.C.A. 64 (1.1); Ferreira, R.G. s.n. EAC 45493 (2.2), s.n. EAC 48985, s.n. EAC 49905 (2.1); Figueiredo, M.A. 143 s.n. EAC 25822 (2.1); Filho, L.C.O. 17 (2.4); Fotius, G. 4036 (2.4); Freire, F.M.T. s.n. EAC 12942(2.1); Fróes, R.L. 30114 (2.1); Gadelha Neto, P.C. 241 (2.4), 470,908 (2.2), 2443 (2.4), 2645 (2.2); Ganev, W. s.n. HUEFS 13718 (1.1), 1123, 1165 (2.4); Gardner, G. 1946 (2.2); Ginzbarg, S. 856 (2.4); Giulietti, A.M. 1844 (2.4); Grisi Velôso, T.M. 267 (2.4); Grupo Pedra do Cavalo 763 (2.2); Guedes, M.L. 8167 (1.1), 12537 (2.2), 13108 (1.1), 15855, 16101 (2.2), 16103 (2.4), 16146 (2.2), 16128, 16970 (1.1), 16180 (2.2), 16181 (2.4); Hage. J.L. 305 (2.2); Harley, R.M. 16440, 21421, 21458, 22007 (2.4), 27855, 55563, 55564 (1.1), 54647, 54670, 56116 (2.4); Hatschbach, G. 48194 (3.1) 48368 (2.2), 63775 (2.1), 65164 (2.4), 78553 (1.1); Heringer, E.P. 188 (2.4), 17131 (2.5); Jordy Filho, S. 96 (2.2); Kuhlmann, J.G. 74 (3.2); Lacerda, A.V. 37, 142 (2.4), 439 (2.2); Lehutne, F. 475 (2.2); Lewis, G.P. 1194 (2.5), 1870, 1972 (2.4); Lima, D.P. 13235, 13295 (2.4); Lima, H.C. 1606 (2.5), 3877 (3.1), 3912 (1.1), 3933 (2.2), 5437 (2.5); Lima, I.B. 724 (2.4), 867 (2.1); Lima, J.R. 218 (2.1); Lima, M.F. s.n. EAC 33072 (2.1); Lima, V.E. 266 (2.4); Lima-Verde, L.W. 352 (2.2); Lopes, M.M.M. 646 (2.4); Loureiro, D.M. 200 (1.1), 206 (2.3); Martins, M.L.L. 334 (2.4); Martins, P. s.n. EAC 7811 (2.1); Matias, L.Q. 208 (2.1); Matos, F.J.A. s.n. EAC 16933 (2.1); Mattos Silva, L.A. 2281 (2.4); Meireles, J.E. 732 (2.1); Melo, A.C. 5 (2.4); Melo, E. 3550, 3639 (2.3), 6943, 7258 (2.4); Mello, P.A. 181 (2.2); Miniz, F.H. 142 (2.1); Miranda, A.M. 5307, 5340 (2.1), 5657 (2.4); Miranda, C.A. 42 (1.1); Miranda, E.B. 79, 832 (2.4); Mori, S.A. 11086, 12247 (1.1); Moro, M.F. 374 (2.1); Nascimento, L.M. 483 (2.2); Navarro, A. s.n. JPB 658 (2.1); Neves, S.P.S. 278, 348 (2.3); Nunes, T.S. 370 , 480 (2.4); Oliveira, E.L.P.G. 727 (2.4); Oliveira, M. 2475 (2.4); Oliveira, M.V.M. 710 (2.4); Oliveira, R.C. 1963 (2.2); Pereira-Silva, G. 9119 (2.4); Pinheiro, R.S. 281 (2.4), 1330 (2.2); Pinto, G.C.P. 106 (2.4), 242 (1.1); Pontes, A.F. 373 (2.1); Ponte Filho, F.A.M. 40 (2.1); Porto, P.C. 
2504 (2.2); Queiroz, L.P. 3253 (2.4), 3406 (1.1), 3423 (2.4), 3467, 3550 (1.1), 3638 (2.4), 3973 (2.3), 6118, 7017 (2.4), 7085 (1.1), 7205 (2.4), 7287 (2.3), 7624 (2.5), 7670 (1.1), 7951 (2.4), 9803 (2.2), 9813, 9984 (1.1), 12720 (2.2), 12780 (3.2), 12812 (2.2), 13031 (2.4); Quinet, A. 707 (2.5); Ramalho, F.B. 11 (2.4), 30 (1.1); Ribeiro, R.D. 1196 (2.1), 1525 (2.5); Ribeiro, T. 75 (2.4); Rocha, R. 2206 (2.4); Sampaio, A. 5634 (2.1); Santos, R.M. 1713 (2.2); Sarmento, A.C. 872 (1.1); Silva, B.M. da 46 (3.1); Silva, C.C. s.n. IPA 85611 (2.4); Silva, D.F. 681 (2.1); Silva, F.H.M. 436 (2.4); Silva, G.P. 3087, 3631 (2.2); Silva, M.C. s.n. EAC 44368 (2.2); Silva, R.M. s.n. CEPEC 40597 (1.1); Silva, R.R. 362 (2.1); Silveira, A. 867 (2.2); Soares, D.G. s.n. IPA 66479 (2.4); Sobrinho, M.S. 295 (2.1); Souza, A. 1669 (2.5); Souza, E.B. s.n. EAC 21911 (2.2); Souza, E.R. 402 (2.4), 940 (2.5); Vasconcellos, J.M. 587 (2.1); Xavier, H.S. s.n. IPA 85107 (2.4); Zehntner, L. 4031 (2.4). 